
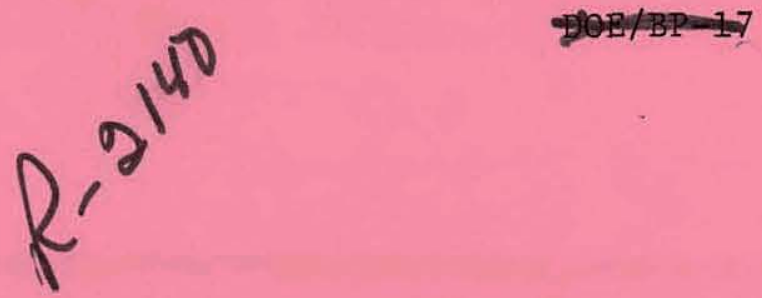

\title{
WIND ENERGY INTEGRATION STUDY
}

\author{
Prepared by \\ DIVISION OF POWER RESOURCES \\ BONNEVILLE POWER ADMINISTRATION
}

Portland, Oregon

August 1980 


\section{DISCLAIMER}

This report was prepared as an account of work sponsored by an agency of the United States Government. Neither the United States Government nor any agency Thereof, nor any of their employees, makes any warranty, express or implied, or assumes any legal liability or responsibility for the accuracy, completeness, or usefulness of any information, apparatus, product, or process disclosed, or represents that its use would not infringe privately owned rights. Reference herein to any specific commercial product, process, or service by trade name, trademark, manufacturer, or otherwise does not necessarily constitute or imply its endorsement, recommendation, or favoring by the United States Government or any agency thereof. The views and opinions of authors expressed herein do not necessarily state or reflect those of the United States Government or any agency thereof. 


\section{DISCLAIMER}

Portions of this document may be illegible in electronic image products. Images are produced from the best available original document. 


\title{
WIND ENERGY INTEGRATION STUDY
}

\author{
Prepared by \\ Division of Power Resources \\ Bonneville Power Administration \\ Portland, Oregon
}

Contributors

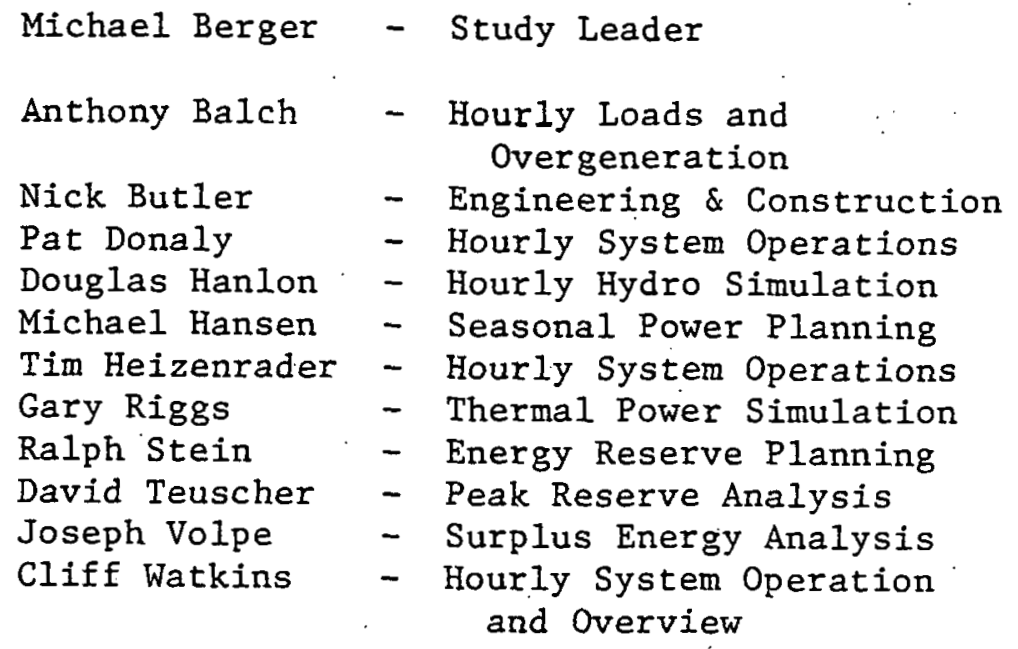




\section{Wind Energy Integration Study}

\section{Executive Summary}

The overall objective of this study was to investigate the feasibility of integrating a simulated 3000 megawatt (MW) wind energy conversion network into the Pacific Northwest hydro-thermal generation system. The specific purpose was to identify those significant effects which require planning consideration and further study prior to extensive development of wind energy. The following areas were identified for preliminary analysis:

1) Seasonal Power Planning (Regulation), 2) Secondary Energy (Surplus),

3) Energy Reserve Planning, 4) Peak Reserves, and 5) Hourly Planning.

The wind energy network utilized for this study was developed by Oregon State University. This network consists of six multi-turbine stations located at various locations in the Pacific Northwest. The output of this network was determined by applying a wind turbine characteristic curve to the hourly average wind velocities recorded at each station for the period December 1, 1976 to November 30, 1977. The network includes a total of 965 turbines with 2.5 and $4.5 \mathrm{MN}$ unit ratings. This yields a total capacity of $3022.5 \mathrm{MW}$. Capacity factor for the year under consideration equaled $33 \%$.

Principal conclusions of this study are as follows:

1. Generation from the wind should be considered a firm energy resource during a critical water year and no capacity credit should be granted for the network under study, at least until 
additional studies are performed. Gross energy production of the $3000 \mathrm{MW}$ network studied equaled about 1000 average megawatts. Assumming worst case operating and streamflow conditions, up to $40 \%$ of this energy would not be useable. Additional studies are necessary to determine the characteristics of the optimum wind network which would maximize the net energy production.

2. The Columbia River Power System can assimilate at least 3000 MW of wind power without violating existing seasonal reservoir and hydraulic operating constraints. Hourly studies, however, indicate up to a $24 \%$ increase in the number of hours during which flow constraints are observed. Maximum change of tailwater and forebay elevations, maximum rate of houriy discharge, and average weekly generation are also impacted by the addition of the $3000 \mathrm{MW}$ network. Hourly impacts may be sensitive to wind network configuration. Further studies are necessary to completely evaluate impacts on hourly operations.

3. The $3000 \mathrm{MW}$ wind power system under study, would force overgeneration amounting to about 40 average megawatts per year. (Overgeneration is the power available when residual load drops below the generation produced from minimum streamflows.) This increment of energy would be a subtraction from the value of the wind energy as a firm resource. The overgeneration occurs primarily in the July-October time period with maximum overgeneration occuring in September. If additional minimum streamflow constraints are put on the Federal Columbia River Power System (FCRPS), the overgeneration will increase. 
4. Given the 1985 load-resource (1979 PNUCC West Group Forecast), which shows a firm deficit of $1490 \mathrm{MW}$, the wind system under study would free secondary energy allocated to this deficit without the wind network and would increase export potential, by about 640 average megawatts. $47 \%$ or about 300 MW of this potential would be marketable over existing intertie capacity. In the 1990 load-resource condition, which shows a firm surplus of $152 \mathrm{MW}$, the export potential increases to about $820 \mathrm{MW}$ assuming no transmission capacity constraint.

5. Given the 1979 PNUCC West Group forecast of loads and resources, and assuming that the gross energy production of the wind network could be assimilated into the existing system, the cumulative probability of insufficient firm energy load carrying capability thru 1990 would decrease from $81 \%$ without wind to $36 \%$ with wind. For total loads the cumulative probability through 1990 of an insufficency decreases from $98 \%$ to $90 \%$ due to the wind network under study.

6. Given that: (1) the hydro system receives the full burden of absorbing the variation in wind power output, (2) wind generation cannot be forecast on a short-term basis, and (3) a median streamflow level occurs, approximately one quarter of the annual energy production from the n'etwork studied would not be useable due to scheduling and operating difficulties imposed by the FCRPS.

Recommendations are made to initiate additional studies which concentrate on real-time operational aspects of scheduling and dispatching a wind resource. 
TABLE OF CONTENTS

PAGE

Executive Summary . . . . . . . . . . . . . . i

I. Introduction . . . . . . . . . . . . . . . 1

Objective

Areas of Investigation

II. Wind Network Description . . . . . . . . . . . 5

III. Study Methodology and Results . . . . . . . . . . . 9 Seasonal Power Planning

Secondary Energy Analysis

Energy Reserve Planning

Peak Reserve Analysis

Hourly System Operations

Hourly Hydro Simulation

Operational Aspects of Wind Energy

Wind Energy Predictability

Operation Flexibility

Overgeneration Analysis

IV. Summary of Results : . . . . . . . . . . . . . 41

V. Recommedations for Future Work . . . . . . . . . . . 44

Glossary .. . . . . . . . . . . . . . . . . . 46

Appendices .. . . . . . . . . . . . . . . 50 


\section{Introduction}

\section{Background}

The Bonneville Power Administration (BPA) contracted with Oregon State University to develop methods of estimating mean wind power and variability of wind. power at a number of selected sites in the Northwest on an hourly, monthly, and seasonal basis. The methods developed in this effort will be used to perform improved analysis of the operational impacts on the hydro-thermal generation system. Prior to these detailed analysis it is necessary to identify key operational impacts and perform a preliminary analysis of these impacts in order to define and scope future efforts.

BPA's Division of Power Resources established a task force to conduct this preliminary analysis of the feasibiltiy of integrating a diversified network of large wind energy conversion systems (INECS) into the Pacific Northwest's hydro-thermal generation system. Most organizational sections in the Branch, together with representatives of BPA's Engineering and Construction were represented on the task force. This report is the result of the task force efforts. 
Objective

This study investigates the feasibility of integrating a $3000 \mathrm{MW}$ wind energy conversion network into the Pacific Northwest hydro-thermal generation system. The purpose was not to provide a detailed investigation of all operational impacts, but rather to identify those significant effects which require planning consideration and further study prior to the development of a greatly expanded program of wind energy in the Pacific Northwest.

\section{Areas of Investigation}

When any new or additional power resource is considered for integration into the existing system, the following areas receive preliminary analysis:

1. Seasonal Power Planning (Regulation)

2. Secondary Energy (Surplus)

3. Energy Reserve Planning

4. Peak Reserves

5. Hourly Planning

The Division of Power Resources currently utilizes planning models for each of the above areas. The approach taken in this study was to utilize the simulated output of a wind power network, and other defined elements, as input to each model and to evaluate the wind component by comparing the model outputs with and without wind (see Figure 1 ). Although this approach has limitations, which vary from model to model, a preliminary 
evaluation of the significance of the impacts is possible and is reported here together with recommendations for further studies.

Assumptions and model limitations are detailed for each area studied. In some cases, assumptions were modified and additional runs were made. In these cases the results from both runs are reported along with an explanation of the differences. Because of the unique impact of the wind resource on hourly system operations, this section contains some additional investigations whose objectives are to provide more insight into the wind resource and to establish a base for subsequent studies. 
FIGURE 1

\section{WIND INTEGRATION STUDY -}

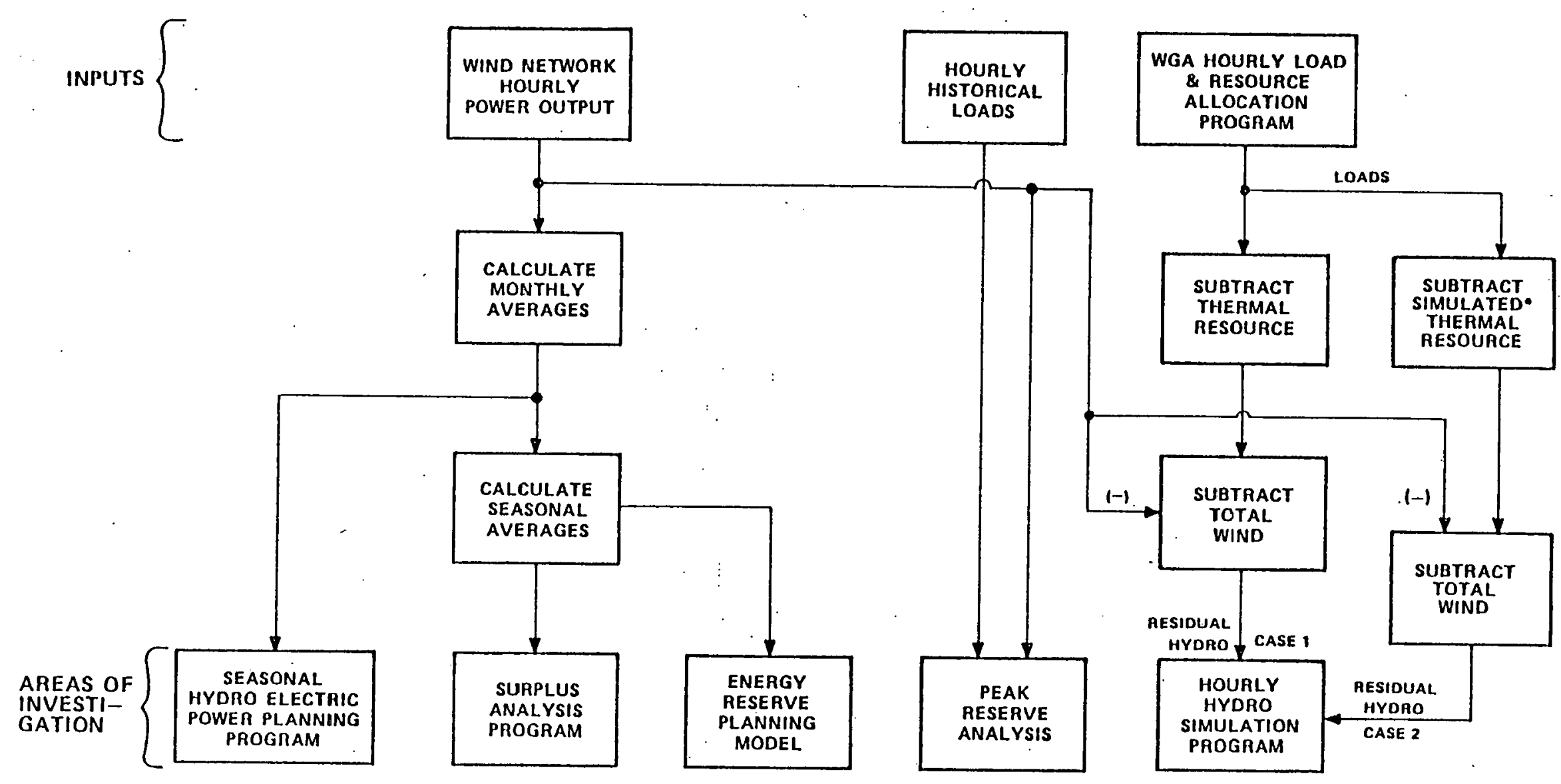

- From Niermal Power Simulator 


\section{Wind Network Description}

The wind energy network utilized in this study is described by Hewson, Baker, Barber, and Peterson ("Executive Summary on Research on Network Wind Power over the Pacific Northwest," Report No. BPA 78-3, Oregon State University). It consists of six multi-turbine stations located at various locations in the Pacific Northwest. Figure 2 shows each station location and Table 1 describes each station's characteristics and output.

FIGURE 2

WIND POWER NETWORK SITE LOCATIONS

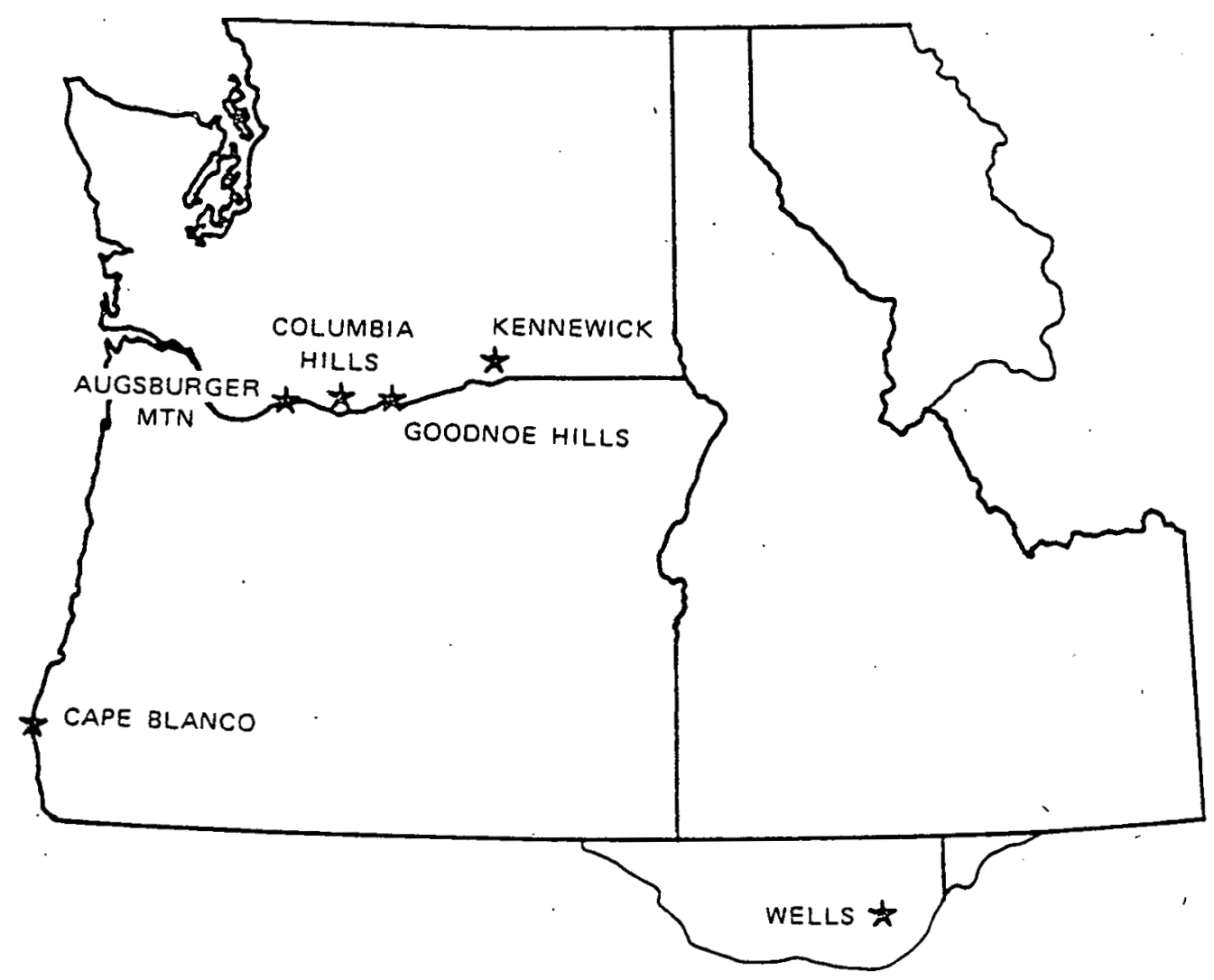


The number of turbines at each site is a function of the land area available. Unit capacity was matched to the average wind velocity at each site so that energy output would be maximized. (See Appendix H) Energy output was determined by applying the wind turbine characteristic curve to the hourly average wind velocities recorded at each station for the period December 1, 1976 to November 30, 1977. (Attachments B through E provide a visual representation of the magnitude and variability of the energy output by station and by total network.) The average wind velocity data from all stations contained a number of data gaps (see Appendix A) which made it impossible to determine what the power output would have been at all times. The percentage of data recovered is listed by station and by month in Tables 1 and 2 respectively. In order to provide continuous data to the models under study it was necessary to devise a method of compensating for the data gaps. Two methods were considered: 1) Simulate the missing data utilizing statistical relationships developed from the available data or 2) Fill-in the data gaps station-by-station by moving adjacent blocks of data into the gaps:

The first method was rejected because of time constraints: A statistical model of the network wind time series is under development at Oregon State University under BPA contract. This model will be used in subsequent studies. The second method was selected because, with only simple data manipulations, it provides a complete and sufficiently accurate data sat for the various models used in the study. 
The average network energy output, capacity factor, and average power output are listed in Table 2 for each month. These monthly averages were utilized as input to the Hydro Electric Power Planning Program (Regulation), the Surplus Analysis Program, and the Energy Reserve Planning Model.

Table 1

WIND ENERGY INTEGRATION STUDY SITE DATA

\begin{tabular}{|c|c|c|c|c|c|}
\hline SITE & NO. OF TURBINES I/ & $\begin{array}{c}\text { UNIT } \\
\text { CAPACITY } \\
\text { (MW) }\end{array}$ & $\begin{array}{l}\text { SIZE } \\
\text { (MW) } \\
\end{array}$ & $\underline{\mathrm{V}(\mathrm{MPH})} 2 \mathrm{I}$ & $\begin{array}{r}\% \text { DATA } \\
\text { RECOVERY } \\
\end{array}$ \\
\hline AUGSPURGER MOUNTAIN & 15 & 4.5 & 67.5 & 16.7 & 86 \\
\hline COLUMBIA HILLS. & 60 & 2.5 & 150.0 & 13.5 & 79 \\
\hline GOODNOE HILLS & 90 & 4.5 & 405.0 & 17.2 & 91 \\
\hline KENNEWICK & 400 & 2.5 & 1000.0 & 16.7 & 93 \\
\hline CAPE BLANCO & 200 & 4.5 & 900.0 & 18.1 & 90 \\
\hline WELLS & $\underline{200}$ & 2.5 & 500.0 & 15.8 & 69 \\
\hline NETWORK TOTAL & 965 & & 3022.5 & & \\
\hline
\end{tabular}

I/. Boeing turbines

2/ Mean annual wind speed for the period December 1976-November 1977 
Table 2

WIND NETWORK ENERGY OUTPUT

\begin{tabular}{|c|c|c|c|c|c|c|}
\hline MONTH & (MWH) & $\times 1000$ & OUTPUT & $\begin{array}{l}\text { CAPACITY } \\
\text { FACTOR }(\%)\end{array}$ & $\begin{array}{l}\text { AVERAGE } \\
\text { MEGAWATTS }\end{array}$ & $\begin{array}{r}\text { \% DATA } \\
\text { RECOVERY } \\
\end{array}$ \\
\hline DEC 76 & & 566 & & 25 & 761 & 80 \\
\hline JAN 77 & & 491 & & 23 & 660 & 81 \\
\hline FEB 77 & & 708 & & 35 & 1054 & 73 \\
\hline MAR 77 & & 902 & & 40 & 1212 & 91 ) \\
\hline APR 77 & & 678 & & 31 & 942 & 95 \\
\hline MAY 77 & & 764 & & 33 & 1027 & 90 \\
\hline JUN 77 & & 811 & & 38 & 1126 & 95 \\
\hline JUL 77 & & 885 & & 38 & 1190 & 84 \\
\hline AUG 77 & & 851 & & 37 & 1144 & 85 \\
\hline SEP 77 & & 669 & & 32 & 929 & 84 \\
\hline OCT 77 & & 733. & & 31 & 985 & 80 \\
\hline NOV 77 & - & 757 & & 37 & 1051 & 81 \\
\hline & & & $\begin{array}{l}\text { Annual } \\
\text { Out }\end{array}$ & erage Network & 1007 & \\
\hline
\end{tabular}




\section{Study Methodology and Results}

Seasonal Power Planning (Regulation)

The Seasonal Power Planning Program is a hydro-electric model that simulates reservoir and hydro generation operations on an average monthly basis. The estimated monthly thermal resource schedule is subtracted from the projected loads to determine the residual load to be met by the hydro system. This residual load is then adjusted by a constant "bias" until the hydro system exactly meets the residual load. The "bias" can be either sign representing either a deficit or a firm energy surplus.

The monthly average output of the wind network (see Table 2) fluctuates slightly (range $=552$ average megawatts) relative to the total system resource $(23,730$ average megawatts) and can be considered as constant. A constant resource will affect only the "bias" and not the basic shape of the hydro regulation. Hence, no new seasonal reservoir regulation studies were deemed necessary for this study. It can be said, however, that since the wind network under study would reduce firm energy deficits, integrating the wind with the Federal Columbia River Power System (FCRPS) would reduce the magnitude of seasonal reservoir drafts for firm loads.

\section{Secondary. Energy Analysis}

Secondary Energy Analysis was done with the Surplus Analysis Program. This program simulates the distribution of surplus energy to various secondary markets. Inputs include: average monthly values of surplus energy and 
surplus capacity for 40 water conditions from a simulated hydro regulation (obtained from Hydro Electric Power Planning Programs), amounts of additional energy from sources such as wind to be added, amounts of energy and capacity required by various secondary energy markets and the ability of each market to accept energy off-peak, the priority of service to the secondary markets, and adjustments to account for such things as maintenance and reserves. The program computes, sequentially for each market, the amount of surplus energy and capacity available, the service to the market, the amount of surplus energy and capacity left for remaining markets. Eventually, all the markets are served, and any surplus energy left over is "unused". Outputs include listings of: the surplus energy. and surplus capacity, the size of each market, the service to each market, and the amount of unused energy left over, all in average monthly values for each of 40 different historical streamflow conditions. In addition, the program computes 40-year average values and 99-year average values based on the 40 years of streamflow record.

Three runs were made for both 1985 and 1990: 1) No wind, 2) With wind (no peaking credit), and 3) With wind (with $1000 \mathrm{MW}$ peaking credit). Under both peak and no peak assumptions wind energy is treated as additional surplus energy, and is served subject to secondary market constraints such as total amount of surplus energy and surplus peak available, and ability of the market to accept energy off-peak. The results of these runs are summarized in Table 3. 
The second run assumes that no wind capacity could be depended upon to meet peak loads. This increases the total amount of average surplus energy in the simulated system. However, with no extra capacity available to back up the additional displacement of thermal markets or the extra service to the industrial or Northwest export market, a significant percentage of the surplus wind energy, $64 \%$ in 1985 and $50 \%$ in 1990 , is not usable. Industrial interruptible increased by only $13 \%$ in 1985 and 1990 respectively.

The third run assumes that the amount of wind generated capacity is equal to at least the average monthly energy. This additional capacity makes the surplus energy more marketable, particularly in the Pacific Northwest. This is due to the Pacific Northwest's markets requirements for more peak service to accompany the energy. Export markets increase only about $18 \%$ over the "no wind" case. Unused energy still increases over the "no wind" case but only by $32 \%$ for both 1985 and 1990. The additional unused energy would result in increased spill unless provisions were made for storage (e.g. pumped hydro). Spill could also be reduced by providing more transmission to the Pacific Southwest. Overall, it can be concluded that a large block of wind energy would impact distribution of surplus energy. The effect of these changes on surplus energy does not appear to pose a technical impediment to the integration of a large block of wind energy. 
TABLE 3

SBCONDARY ENERGY ANALYSIS WITH 1007 AVERAGE ANNUAL MH OF ENERGY

- 99 year fiverage mw -

\begin{tabular}{|c|c|c|c|c|c|c|c|c|c|c|c|}
\hline & & & & & & SECONDARY MARKET & ERVICE & & . & & Unused \\
\hline & $\begin{array}{l}\text { Plrw } \\
\text { Deflclt/ } \\
\text { Surplus }\end{array}$ & $\begin{array}{l}\text { Surplus } \\
\text { Above } \\
\text { FEICC }\end{array}$ & $\begin{array}{l}\text { Mt. States2/ } \\
\text { Imports } \\
\end{array}$ & $\begin{array}{l}\text { Exlsting } 3 / \\
\text { Thermal } \\
\end{array}$ & $\begin{array}{l}\text { Conbustions/ } \\
\text { Turbines }\end{array}$ & Interruptible $5 /$ & $\begin{array}{l}\text { Energy6/ } \\
\text { Payment }\end{array}$ & Export ?/ & Coal $\underline{\text { Cof }}$ & Nuclear $0 /$ & \\
\hline \multicolumn{12}{|l|}{ 19205 } \\
\hline Ho wind & $(1490)$ & 3990 & 60 & 25 & 19 & 277 & 206 & 1482 & 266 & 191 & 411 \\
\hline WIth wind & $(1490)$ & 3980 & 66 & 27 & 21 & 313 & 224 & 1781 & 307 & 218 & 674 \\
\hline Gain due to wind & & & 6 & 2 & 2 & 36 & 18 & 299 & 41 & 27 & 263 \\
\hline with wind + peak !' & $(1490)$ & 3900 & 76 & 29 & 36 & 434 & 222 & 1755 & 331 & 204 & 545 \\
\hline Galn due to peak 1/ & & & 10 & 2 & 15 & 121 & (2) & (26) & 24 & (14) & (129) \\
\hline Gain over "No wind" & & & 16 & 4 & 17 & 157 & 16 & 273 & 273 & 13 & 134 \\
\hline \multicolumn{12}{|l|}{1990} \\
\hline No wind & 152 & 3452 & 64 & 37 & 56 & 497 & 0 & 1084 & 393 & 614 & 459 \\
\hline With wind & 152 & 3852 & 64 & 40 & 67. & 674 & 0 & 2247 & 420 & 803 & 649 \\
\hline Gain due to wind & & & 0 & 3 & 11 & 177 & 0 & 363 & 35 & 191 & 230 \\
\hline with wind + peak $1 /$ & 152 & 3052 & 66 & 42 & 98 & 811 & 0 & 2247 & 438 & 739 & 602 \\
\hline Galn due to peak I/ & & & 2 & 2 & 31 & 137 & 0 & (30) & 10 & (64) & (a7) \\
\hline Galn over "No wind" & & & 2 & 5 & 42 & 314 & 0 & 333 & 45 & 127 & 143 \\
\hline
\end{tabular}

1/ Wind peak credlt assumed to be equal to seasonal wind average.

2f I'hls displaceabje inarket conslgts of high cost therinal resources Imported from Idalio, Utah, and Montana.

3/ This displaceable market conslsts of high cost, ofl fired and diegel generation within the region.

4/ This displaceable market consigts of high cost conbustion turblnes located within the region.

5f Phls market is the top quartlle of BPA's industrlal loàd.

6/ IIIs displaceable market represents the energy payment owed to apa by soucliwest utillties for contracted Capacity/Energy Excliange. (apA exports peak. recelves the energy back off-peak plus recelves an energy payment for the service.)

If fixport represents that energy wistcli can be sold to the Soutliwest over the Pacific Intertle.

af Inese markets represent low cost coal and nuçlear resources which can be displaced after previous markets are servlced. 
The Energy Reserve Planning Model is a Monte Carlo simulation model of the West Group Area's load resource plan. It requires as input a proposed, generation plan, load forecast, existing and programmed hydro, and thermal energy capabilities. The program computes statistical information on surplus or deficit energy balance.

The program operates on a continuous basis, starting at the present and going eleven years into the future, through a sequence of four month seasons. In each season, the load, streamflow capability and thermal plant availabilities are selected by a random process from appropriate probability distributions. The probabilities computed for each season, are based on the success or failure of meeting loads within prescribed constraints on the use of hydro Firm Energy Load Carrying Capability (FELCC). Output is expressed in two tables: 1) the probability of failing to meet firm loads within the FELCC constraint, and 2) the probability of failing to meet total loads. These outputs are shown in Appendix G Tables GI and G2 for the eleven year period ending with 1990.

The Energy Reserve Planning Model was then run for the same period with wind included as a firm generating resource. This resource was defined by calculating seasonal averages from the monthly averages given in Table 2. The inclusion of such a large firm resouce resulted in a substatial drop in probability values as shown in Appendix G Tables G3 and G4. For example, the cumulative probability of insufficlent firm energy load 
carrying capability thru 1990 would decrease from 81\% without wind to $36 \%$ with wind. For total loads the cumulative probability through 1990 of an insufficency decreases from $98 \%$ to $90 \%$ due to the wind network under study.

This apparent improvement in the energy reserve position must be tempered by a more detailed analysis of the modeling assumptions and procedures.

The first and most critical assumption is that the gross energy production of the wind network could be assimilated into the existing system. Subsequent sections of this study address some of the difficulties in assimilating the entire output of the wind retwork. The net result of a reduced amount of energy assimilated would be a reduction of the impact on the probability of not meeting loads. A more precise solution could be derived by treating the seasonal wind as a stochastic variable. Studies underway at Oregon State University are intended to develop. techniques for treating the wind as a stochastic variable.

The second assumption was that forced outages and maintenance activities were already reflected in the monthly average energy outputs. The reason for making this assumption was the lack of data regarding the availability of wind machines which have not as yet been manufactured and tested to verify their estimated performance. Assuming a minimum availability goal of $90 \%$. for the turbines used in this simulated network, 
the net effect would have been to lower the seasonal average outputs by 10\%. Although this would have affected probability calculations, the effect would have been small considering the dramatic drop in probability figures.

The final element requiring consideration is the effect of the modeling process itself. By utilizing seasonal averages and by projecting operation into 1990, many potential difficulties may be overlooked. The net effect of these difficulties is to lower the seasonal averages which are utilized as inputs to the model. Again the result is to raise the probability figures shown in Appendix G Tables G3 and G4.

The analysis of energy reserves does, however, indicate that a 3000 megawatt wind network as described in Section II does produce enough energy to reduce the probability of "resource deficits for projected firm and total loads. The extent of this impact needs to be evaluated in more detail prior to calculation of accurate probabilities.

\section{Peak Reserve Analysis}

The model used to calculate loss of load probabilities requires the following inputs for each generating unit: (1) maintenance schedule, (2) forced outage rate, and (3) peak firm capacity. If each wind farm is considered as a generating unit, both the maintenance schedule and forced outage rate could be estimated from available design literature. However, the peak capacity credit is more difficult to assess. These difficulties are compounded by the fact that the model, in its present 
form, requires a single number for peaking credit and cannot handle a probablistic description of peaking capacity. Consequently, for the study, the analysis involved an examination of hourly network output data to determine what, if any, capacity credit could reasonably be assigned to wind.

Figure 3 represents one approach to quantify the capacity credit available. The hourly wind power output of the simulated network was overlapped with the coincident hourly loads for the same period. For each day of the period, the hour of peak load was identified. For that hour of peakload, the total network output was noted and converted to a percent of total network capacity. This was done for each day of the one-year period, and the data was accumulated to plot the Percent Network Output versus the Probability of Occurrence at Peak Daily Load. Based on this one year of data, 6 percent of the network capacity (I8I MW) would be available 90 percent of the time when peak loads occur. Further down the curve, $907 \mathrm{MN}$ (30 percent of network) would be available 50 percent of the time. This simple type of analysis has three deficiencies: the apparent peaking capacity available a significant portion of the time is relatively small by conventional standards, (2) the probabilistic approach for estimating wind can not be readily interpreted, and (3) the one-year data base is too small to make broad generalizations regarding available peaking. This analysis suggests that the peaking capacity of the simulated wind network is relatively small.

Overall, the simulated wind network does not provide enough data to make an estimate of peak capacity for use in calculating loss of load 


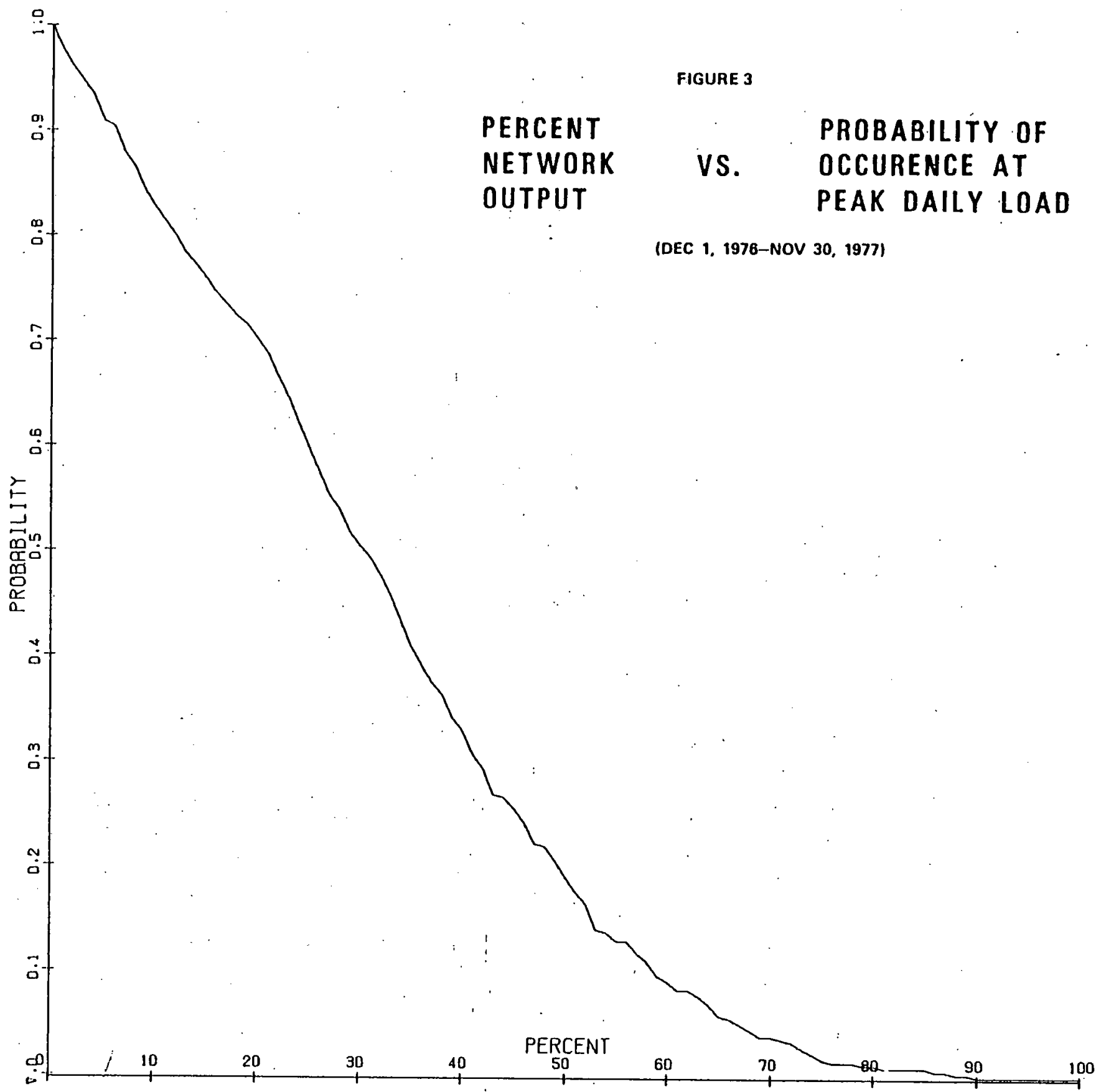


probabilities. However, it also does not conclude that a reasonable peaking capacity is impossible for the proposed wind network. Further investigation of the peaking capacity credit problem is now underway in the Power Investigation Branch. This investigation will utilize a modified version of the Coordination Analysis Reserve Program to accept a capacity loss distribution for the wind sites instead of the commonly used capacity and forced outage ratings.

Eourly System Operations

Integration of a large block of wind energy with the planned FCRPS has the greatest impact on the short term (hourly) operation of the system. Questions arise on how the system can tolerate the rather large variability (coefficient of variation $>0.60$ ) in output from networks with up to 3000 MN of installed capacity. The unpredictable component of the variability will contribute to increased problems with flexibility in scheduling the daily generation of the system with some consequent loss in average operating head at controller plants. In addition, tailwater and forebay variations can be expected to increase as controller plants operate to smooth the random-like wind energy to load. This section of the report discusses these aspects of integration problems and looks at the forecasted peaking capability of the system as it affects shaping the wind energy over peak load periods. 
Hourly Hydro Simulation - The BPA hourly hydroelectric simulation program (Hourly Pondage Program) is used to study the operation of the hydroelectric power system in response to various load shapes (Residual Load) of 168 hour duration ( 1 week). In addition to 168 hourly loads, program input represents each hydro project in the system with such parameters as are necessary to compute generation and route streamflow in the proper path through the system. Program logic is lengthy and complex and will not be discussed here. Output gives a detailed, hour-by-hour printout of each plant's turbine flow, spill (if any), head, and end-of-hour forebay and tailwater elevations. A summary is provided at the end of the output which shows; among other things: 1) the maximum hour's generation for each plant, 2) the average load factor (percent) for each plant, 3) average flow to generation conversion factors $(H / K)$ and average generation for each.plant, 4) average head for each plant, 5) average spill and turbine flow for each plant, and maximum change in forebay and tailwater elevations for each plant, both hourly and daily. A total of 38 West Group Area (WGA) hydro projects were used in the BPA hourly hydroelectric simulation program. It should be noted that the simulation program is only capable of running 168 hours of loads (one week), so it is assummed that one week is representative of any given month.

-The simulations are somewhat limited since the program establishes a dispatch schedule based on 168 hours of projected loads. This schedule, in effect, anticipates what the hourly loads will look like for an entire week. This anticipation does" not reflect the uncertainty that would be encountered. with a wind resource from hour-to-hour. Since the wind network under consideration can produce significant hour-to-hour variations which may not 
be anticipated by the weekly schedule, an additional study was undertaken which simulates the impact of the variation on hourly operation.

The methodology consisted of scheduling the weekly operation using the loads from the WGA Hourly Load and Resource Allocation Program. After the operation was scheduled the system was then required to respond hour-to-hour to a modified schedule which incorporated the variability of the wind resource. This variability is represented by a set of additions to the base system load that have the same coefficient of variation' as that exhibited by the wind network data. The assumed level of development for this study is 1990 with 1937 water conditions. Two representative periods of the year have been. studied: August 16-31, generally a period of minimum load, and January, a period of heavy loads. Operational constraints on the river are stricter during August than January. The BPA Hourly Hydroelectric Pondage Program simulates reservoir operation hourly for a maximum of 168 hours of load (one week). It is assumed that 168 hours of load is representative of the two monthly periods (January and August) being considered here.

The Hourly Pondage Program was.first Iun for August and January with 1990 level (WY '37) federal mainstem hourly loads based on the PNUCC West Group Forecast dated April 23, 1979. These runs are to be considered the base cases. The base cases were then compared to FCRPS operation with the addition of variable hour-to-hour load changes due to the attachment of: (1) a 2,000 MW wind generation system and (2) a 3,000 MW wind generation system. The 2,000 iN was simulated by using hour-to-hour variations which were tio-thirds the magnitude of those used for the 3,000 MN network. Due to the random nature of wind, Five different wind load sequences for both 
the 2,000 and 3,000 MN cases were run for January and August. The resulting impacts from five hourly simulations were then compared to each base case. Operational impacts are summarized below and in Figures 4 through 7 .

\section{Meeting Load:}

\section{a. August $16-31$}

The base case met load each hour with no constraint violations. The five 2,000 MW wind cases missed load an average of three hours per week, with a mean overgeneration of 579 MWh and a mean undergeneration of $1,706 \mathrm{MWh}$.

The five 3,000 MW cases missed load an average of four hours per week, with a mean overgeneration of $1,633 \mathrm{MWh}$ and a mean undergeneration of $636 \mathrm{MWh}$.

\section{b. January}

The base case met load each hour with no constraint violations. The five 2,000 MW wind cases each missed load during one hour, with a mean overgeneration of $771 \mathrm{MWh}$. The five 3,000 MW wind cases missed load an average of three hours per week with a mean overgeneration of $1,736 \mathrm{MWh}$. These load misses, of course, have a direct effect on average generation for the week on the system. See Figure 4.

2. Maximum Rise (or Fall) of Discharge During Any One Hour for Mainstem Federal Plants (Coulee, McNary, John Day, The Dalles):

As might be expected, the addition of both 2,000 and 3,000 MW wind load variations significantly raised the maximum change in discharge 
during any one hour for the mainstem plants shown above. These increases did not cause these plants to violate hourly flow constraints, however, which are built into the program.

See Figure 5 for average percentage increases in hourly discharge for the four mainstem plants above the base case. In constructing these simple graphs, both a mean average and an extreme value of the five cases have been used for comparison purposes.

3. Maximum Hourly Rise (or Fall) of Tailwater and Forebay Evelations (Totals for the Ssytem):

As might be expected from observing Figure 5, there were increases above the base case in maximum hourly tailwater and forebay fluctuations. Figure 6 represents Federal system totals for the base case versus means and extremes for the 2,000 and 3,000 MW wind cases.

4. Number of Hours Constraints Were Hit and Conseguently Observed:

Part of the input to the Hourly Pondage Program consists of hourly flow constraints for certain projects. In other words, certain projects are restricted to a certain maximum discharge fluctuation from any one hour to the next. When the program hits this maximum, for a project during an hour, another project (or projects) must be found that are able to "swing" and pick up the difference. Figure 7 compares the base case with the means and extremes for the 2,000 and $3,000 \mathrm{MW}$ cases. 
FIGURE 4
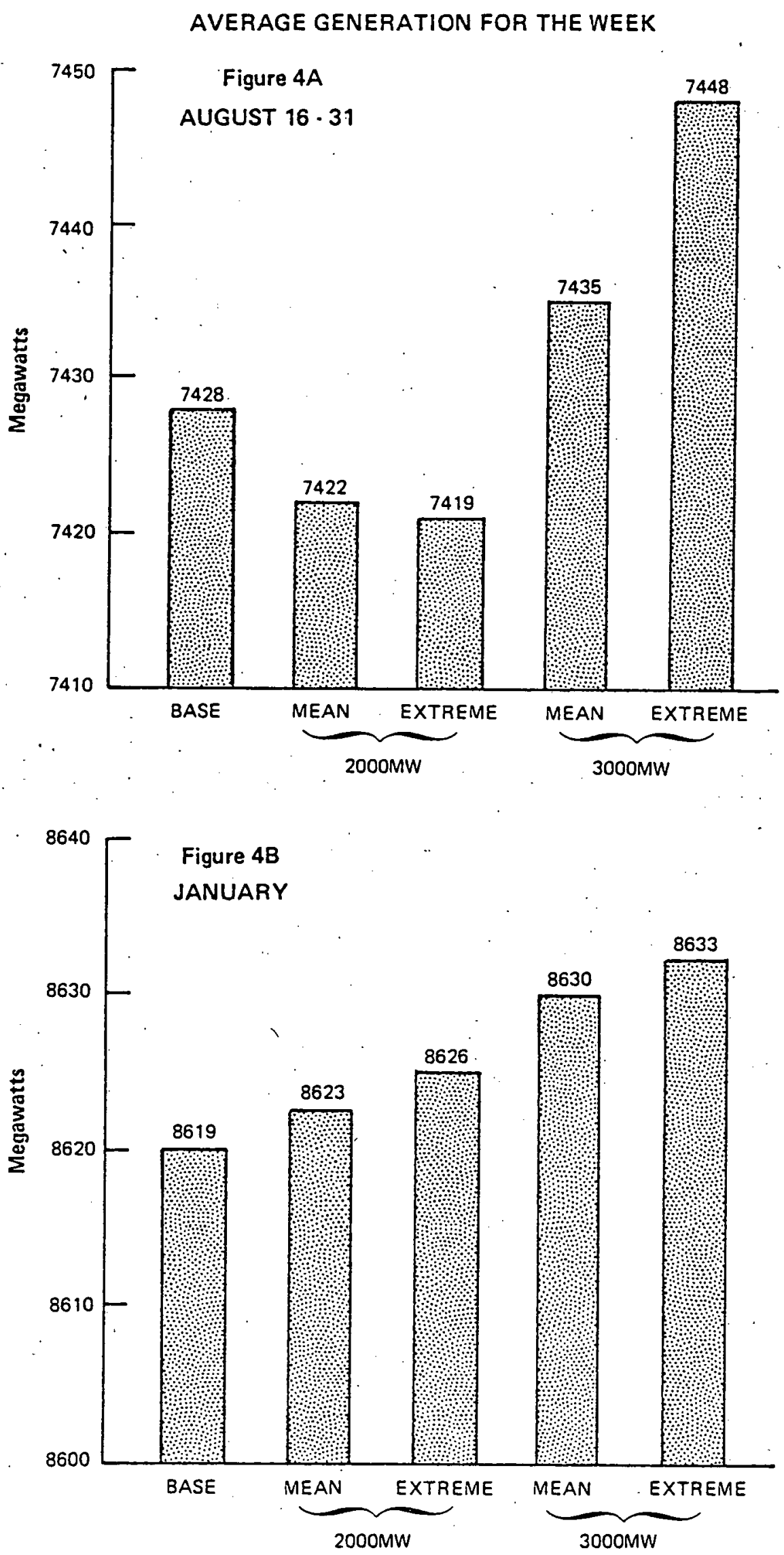
FIGURE 5

MAXIMUM RISE OR FALL OF DISCHARGE DURING ANY ONE HOURAVERAGE PERCENT INCREASE OVER BASE CASE (.Coulee, McNary, John Day, The Dalles)
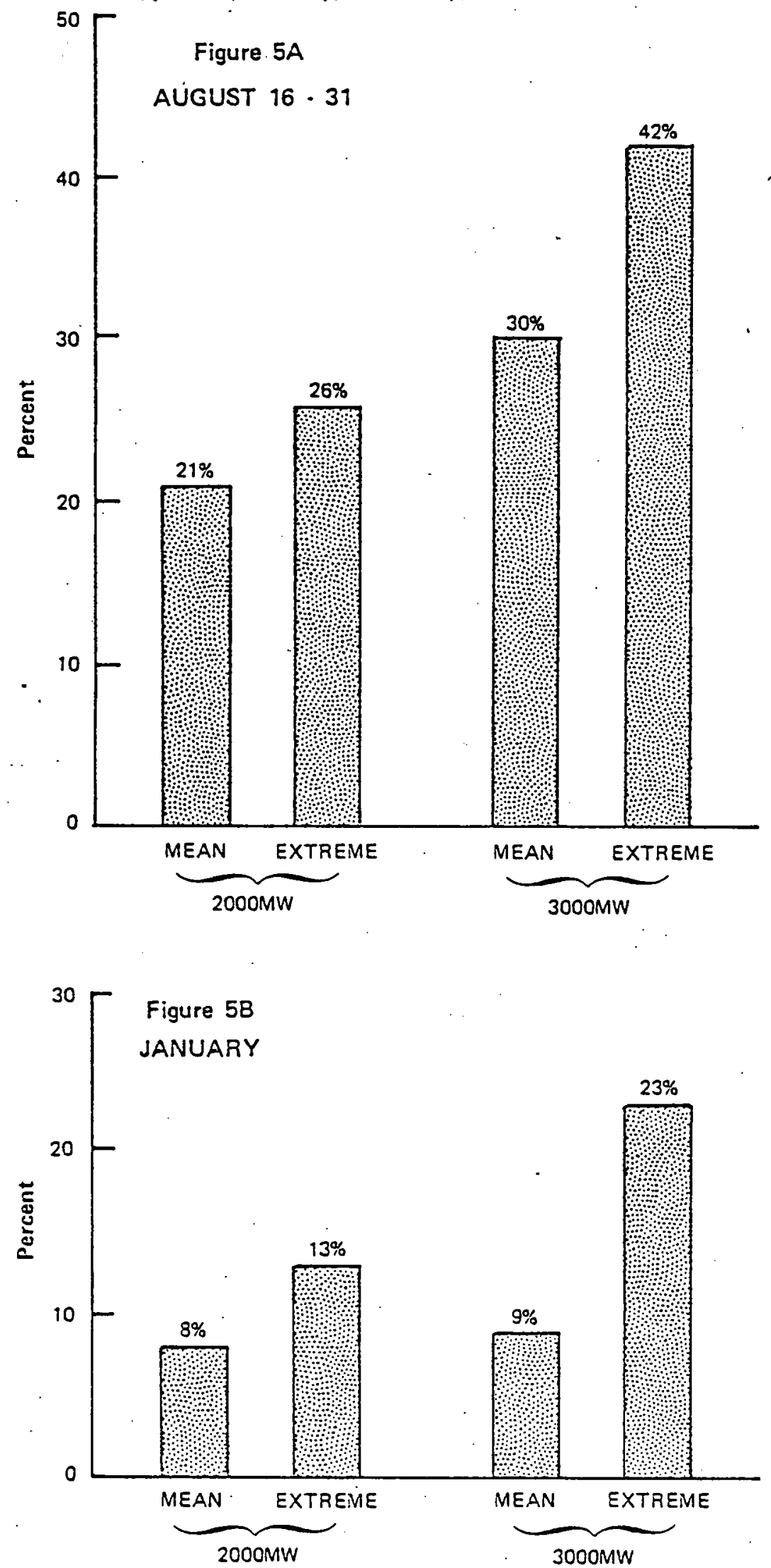
FIGURE 6

MAXIMUM HOURLY RISE (OR FALL) OF TAILWATTER AND

FOREBAY ELEVATIONS (System Totais)

Figure 6A

AUGUST 16 - 31
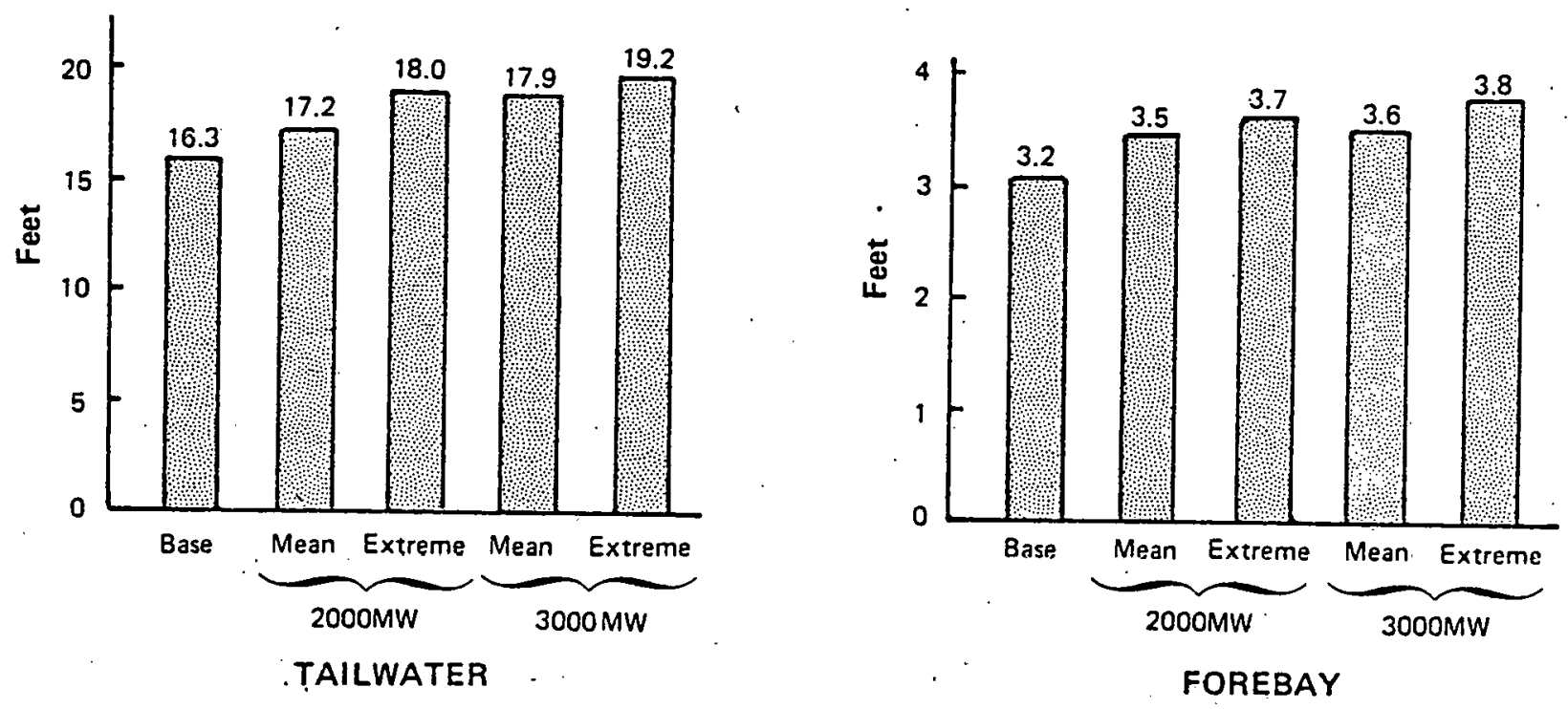

Figure 6B

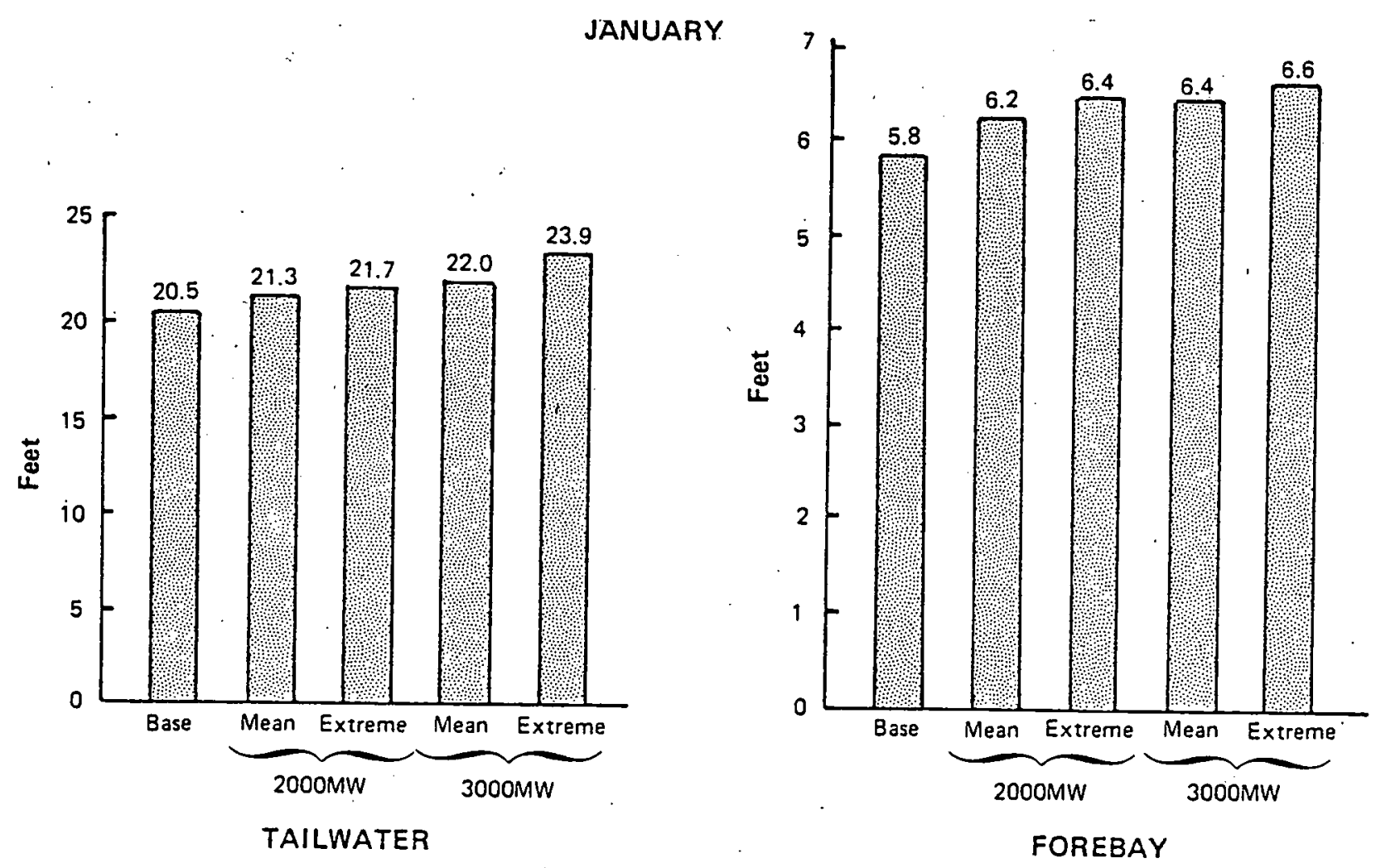


FIGURE 7

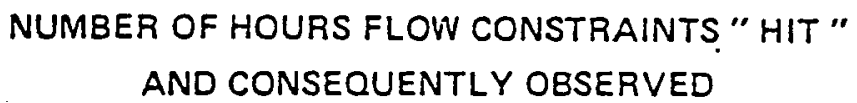

Figure 7A

AUGUST 16.31

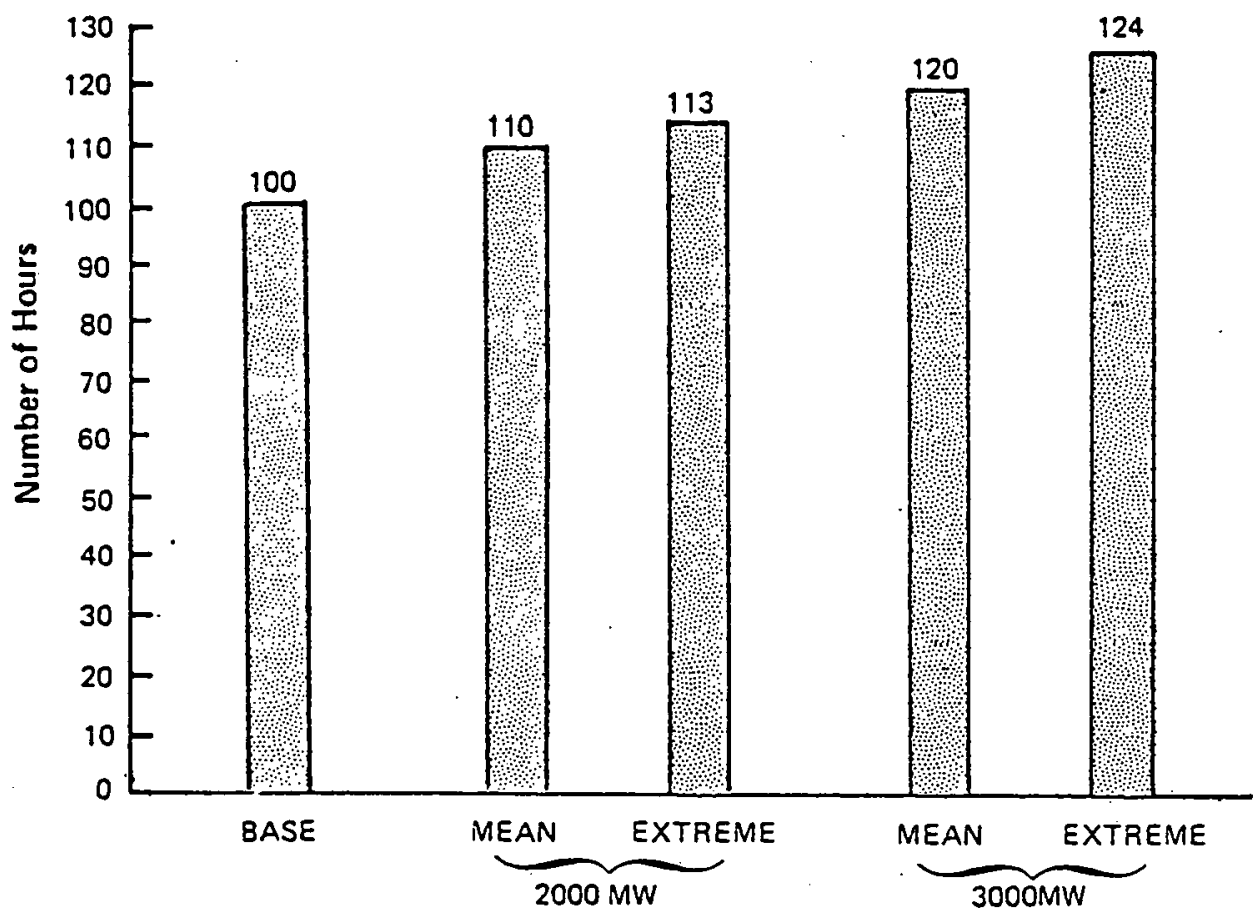

Figure 7B

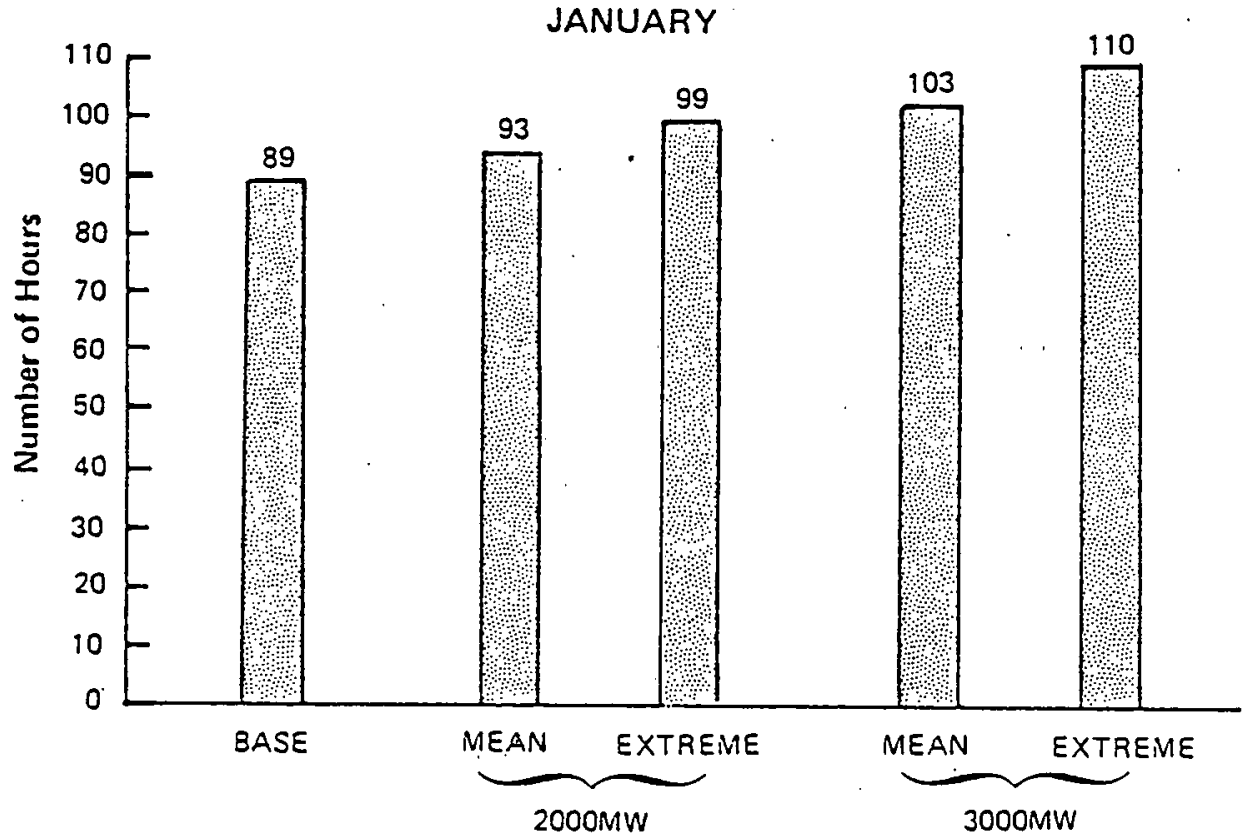


The Hourly Pondage Program configuration for this study assumed that ten projects were allowed to swing in meeting load fluctuations. BPA operations staff currently only use two projects (John Day and The Dalles, or Coulee and Chief) to accomplish this same task. A future series of studies may want to use this 2-project configuration for comparative purposes.

Operational Aspects of Wind Energy - Preliminary studies conducted by Heizenrader and Donaly $1 /$ have attempted to identify and quantify the impacts of potential scheduling and operating difficuties of incorporating a large amount of wind energy resource into the FCRPS. The hourly wind resource used for these studies is the same as identified in Section I of this stuḍ.

The studies focus on the practical day-to-day scheduling and dispatching decisions that will affect the usability of the wind resource. The decrease in usability is converted to a discount to the wind resource in terms of average megawatts which are subtracted from the gross energy production. Table 4 sumarizes the results of this analysis. Explanatory notes are provided to assist in defining each line item.

As shown in Table 4, the net energy production during a median water year is equal to approximately $70 \%$ of the theoretical gross production. The primary assumptions made in calculating these discounts are: (1) the hydro system receives the full burden of absorbing the variation in the power output; and (2) there is no wind forecasting capability. These assumptions are çonservative.

I/ Heizenrader, Tim and Donaly, Pat; Alternate Wind Integration Study (FIRST DRAFT), Bonneville Power Adminiștration; Portland, Oregon; March 10, 1980. 
Heizenrader and Donaly offer a number of mitigating measures that can be taken to reduce scheduling and operating uncertainty. These measures include the following:

1) Smaller Diversified System - The $3000 \mathrm{MW}$ network used in this study has a substantial portion of its total capacity located at two sites (1.e. $1000 \mathrm{NW}$ at Kennewick and $900 \mathrm{MW}$ at Cape Blanco). This magnifies the operating dificiculties since wind lost at one of these sites results in a significant loss of generation. By structuring the system in such a way that only $200 \mathrm{MW}$, for example, were located at any one site the sudden loss of wind would not have as significant an effect. An optimum network would produce as much energy as the 3000 MW facility. used for this analysis but at a considerably lower capital cost.

2) Ramped Shutdown Strategy - The wind turbine operating characteristic curve has an instantaneous cut-out velocity to protect it from high winds. (See Appendix H.) This results in rapid loss of large amounts of generation when a site is experiencing high winds around the cut-out velocity. To reduce this impact an alternate control strategy is offered by which the farm is gradually shut down as winds increase. This could be accomplished by having machines with different cut-out velocities on the same site. Such a strategy could result in an improved energy capture due to the reduced uncertainty.

3) Short-Term Wind Forecasting - The eriergy discounts assume no ability to forecast wind which assumes independence of hourly average wind speeds. It is likely that there is an hour-to-hour dependence which if modeled correctly would aid in the ability to provide short-term forecast of wind generation. 
Table 4

WIND INTEGRATION DISCOUNTS

$3000 \mathrm{MW}$ Network

Energy Discounts

1. Installed Capacity

2. Streamflow Leve1

3. Load Level

4. Wind Level

5. Wind Unit Rower Profile

6. Average Energy, Gross Production

7. Seasonal Wind Shutdown:

Insufficient Hydro AGC*

8. Special Operational Shutdown

9. AGC* Plant Head Loss

10. Reduction Due to Forced Outage

11. Maintenance

12. Average Energy, Net Production

13. Unusable Production: Insufficient Market

14. Average Energy, Net Usable Output

\begin{tabular}{|c|c|c|}
\hline $3,000 \mathrm{MW}$ & $3,000 \mathrm{MN}$ & $3,000 \mathrm{MW}$ \\
\hline Low & Median & $\mathrm{High}$ \\
\hline 1990 & 1990 & 1990 \\
\hline Median & Median & Median \\
\hline Standard & Standard & Standard \\
\hline $1,000 \mathrm{MW}$ & $1,000 \mathrm{MW}$ & $1,000 \mathrm{MW}$ \\
\hline - & $-125 \mathrm{MW}$ & $-250 \mathrm{MW}$ \\
\hline$* *$ & $\approx *$ & $* *$ \\
\hline$-45 \mathrm{MW}$ & $-39 \mathrm{MW}$ & $-34 \mathrm{MW}$ \\
\hline$-98 \mathrm{MW}$ & $-86 \mathrm{MW}$ & $-74 \mathrm{MW}$ \\
\hline$-20 \mathrm{MW}$ & $-14 \mathrm{MW}$ & $-8 M W$ \\
\hline $837 \mathrm{MW}$ & $736 \mathrm{MN}$ & $634 \mathrm{MW}$ \\
\hline
\end{tabular}

See Explanatory Notes.

\section{Pondage Requirements}

15. AGC* Plant Pondage Reservation, Energy Equivalent

Integrating Hydro Capacity

16. AGC* Plant Capacity Reservation $\geq 2,610 \mathrm{MW} \cdots \geq 2,610 \mathrm{MW}$

* Automatic Generation Control

$*$ Not Computable 


\section{EXPLANATORY NOTES \\ for WIND INTEGRATION DISCOUNT TABLE 4}

1. Installed Capacity. Input; Nameplate capacity of proposed wind system.

2. Streamflow Level. Input; study parameter.

3. Load Level. Input; study parameter.

4. Wind Level. Input. Only one year of hourly daca. That daca which is available is presumed to be "typical" and represent a median condition. This analysis further assumes hourly winds to be normally distributed with neither seasonal nor diurnal shape.

5. Wind Unit Power Profile. Input. (Boeing 2.5 and 4.5 WW Operating Characteristic Curves.)

6. Available Energy, Gross Production. Maximum production theoretically attainable. Average annual network output. See Iable 2.

7. Seasonal Wind Shutdown, Insufficient Hydro Automatic Generating Control, AGC. When finflow to AGC plants is sufficiently high, generation control is accomplished through vaste-gate operations; reduced generation is essentially a diversion of water from turbine to spillway. Under such circumstances it is assumed that wind turbines would be shut down; it would be impractical to suffer wear to both hydro and wind units when one can be displaced. Supported by seasonal regulations, this analysis assumes that wind resources will be shut down for the full month of May and the first half of June under median streamflow conditions. Under high streamflow conditions, such as the 1956 water year, it is assumed that wind units will be shut down Erom April 1 through the end of June. Briefly, wind units are assumed to be shut down during periods that seasonal regulations determine average discharges at The Dalles to be in excess of $80 \%$ of that plant's hydraulic capacity. Assuming no seasonal wind shape, this item reduces annual average wind output by $12.5 \%$ in median hydro years and $25 \%$ in high runoff years.

8. Special Operation Shutdown. Special requirements frequently dominate the hydraulic operation of AGC plants, reducing flexibility and thus reducing ability to integrate wind generation. This analysis assumes that wind resource will be shut down for some amount of time to accomodate such operations as necessary for stream gauging, fish flows, geese nesting, construction, Gold Cup races, vessels aground, etc., but assesses no discount.

9. AGC Plant head Loss. To integrate wind generation without causing spill at AGC plants it will be necessary to reserve pondage. Head losses will result. Computations show that, assuming all such pondage is provided at John Day, annual energy losses of about $1.5 \%$ per thousand MW of installed wind capacity will result.

10. Reduction Due to Forced Outage. A forced outage rate of $10 \%$ is assumed. That is, wind units are assumed to be unavailable for service for about five weeks per year due to forced outages. Such outages are assumed to be uniformly distributed throughout the year.

11. Maintenance. Nind units are assumed to require one week of maintenance per year. Maincenance is scheduled uniformly between April 1 and August 31.

12. Average Energy, Net Production. Line 6 less Lines 7 through 11 .

13. Unusable Production, Insufficient Market. This discount is intended to show that part of wind production that is unusable for lack of warket. The Secondary Energy Analysis and Overgeneration Analysis described in Section III of this study assume that the hydro system has been able to assimilate or "capture" the gross energy output of the wind resource. Later studies, reflecting the variable, limited ability of the hydro system to assimilate wind resources will provide accurate assessments of this parameter.

14. Average Energy, Net Usable Output. Line 12 less Line 13.

15. AGC Plant Rondage Reservation, Energy Equivalent. This item shows the anount of pondage required, in Mrn, to accomdate incegration of wind generation. The figure shown includes both space reserved to avoid spill during high wind and water reserved to support hydro generation during slack wind. t failure rate of one hour per week is assumed.

16. AGC Plant Capacity Reservation. This item shows the amount of AGC plant generating capacity that must be reserved for, or dedicated 50 , incegration of the given wind installation. A failure rate of one hour per week is assimed. 
4) Pumped Hydro - A pumped storage/wind turbine system would have the dual benefit of yielding firm capacity and reducing dispatching uncertainty. These benefits would, of course, have to be weighed against the increased capital cost allocated to the wind network.

Wind Energy Predictability - Only a cursory examination of the predictability of the wind has been performed for this special case look at wind integration. A more comprehensive study of predictability involving time series and dynamic meteorlogical approaches is underway at Oregon State University (OSU) under contract with BPA. Also, more definitive studies on the statistical properties of the network described in this report are underway at BPA and will become part of subsequent reports. Until these studies are completed, however, useful insight on predictability can be gained by examination of a simple auto-correlelogram of the output of the wind system.

Figure 8 is the auto-correlelogram function of the output of the $3000 \mathrm{MW}$ system discussed in this report. Data are a one-year set of synoptic hourly observations from the OSU network transformed to values of electrical energy as described earlier. Note that this particular set had a mean energy output of $1006 \mathrm{MW}$ with a standard deviation of $632 \mathrm{MW}$. Plotted on the ordinate is the correlation of the wind energy for the lag shown on the abscissa. For example, the energy at a particular hour chosen at random has a correlation of about 0.90 with energy at the following hour. Likewise, the correlation holds up to 0.60 at 4 hours lag implying significant predictability continuing at this range. By 24 hours the correlation drops to nearly 0.20 (and continues near 0.20 through at least 168 hours) suggesting that more complex processes would be needed for useful prediction at these ranges. 
Figure 8

COEFFICIENT OF CORRELATION (RHO) vs. TIME LAG

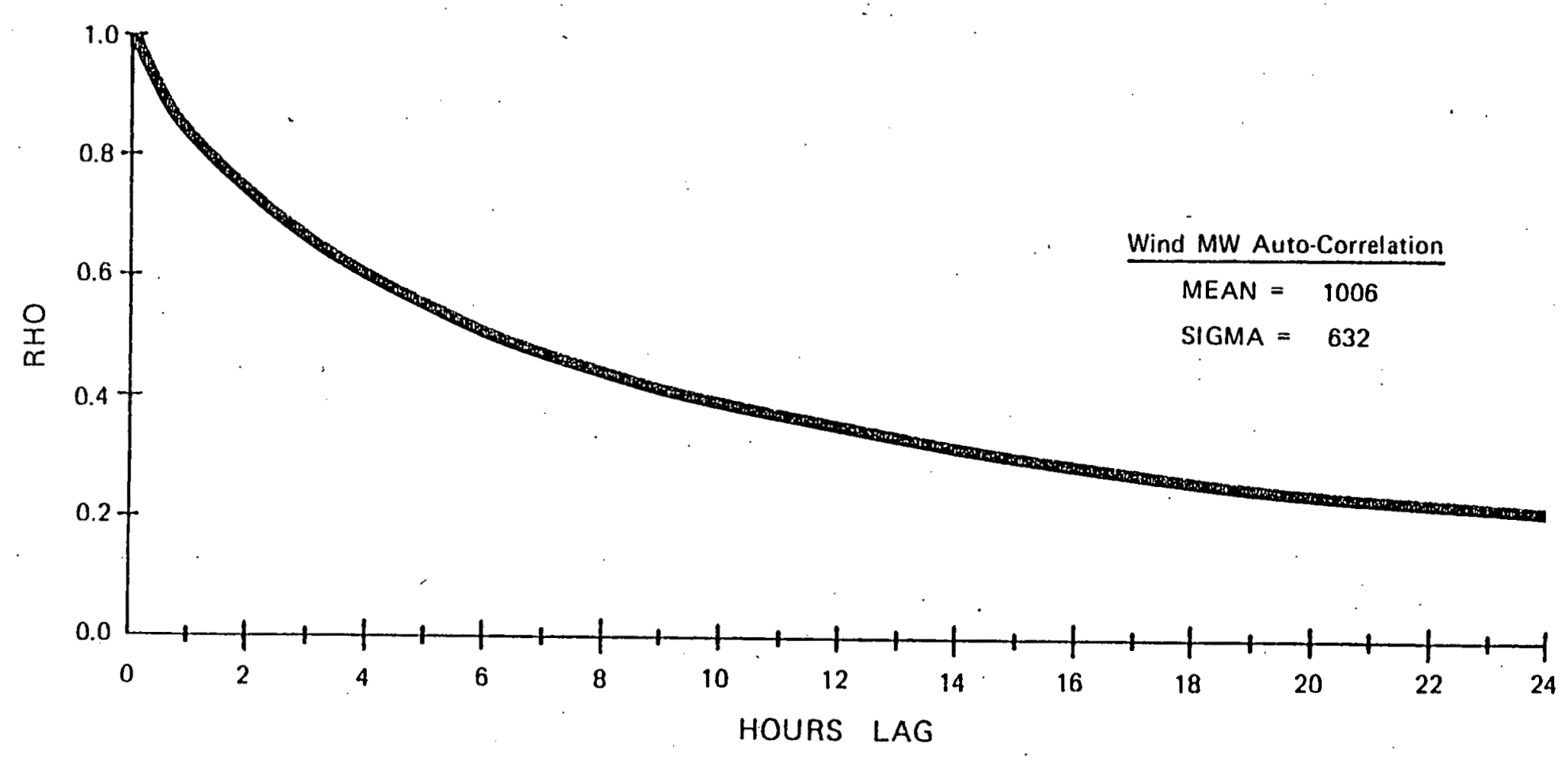


A quick estimate of the magnitude of the predictability that can be achieved by applying an approximate model to predict errors which could result from use of the series correlations. This model is defined by $\sigma_{e}=\sigma_{1} \sqrt{1-\rho_{e}{ }^{2}}$ where $\sigma_{e}=$ the standard deviation of the errors in a simple regression estimate of the energy output at lag " $e$ " having correlation, $\rho_{e}$, with the intitial value of energy output and given a standard deviation, $\sigma_{1}$ of the data sample. Application of this formula to the one-year data set yields the standard deviations shown in Table 5 .

\section{Table 8}

Standard Deviations for the Error of a Simple Linear Regression Estimate of Wind Energy

\begin{tabular}{ccc}
$\operatorname{lag}$ (hours) & $\rho_{\mathrm{e}}$ & $\sigma_{\mathrm{e}}$ (MVI) \\
\hline$\cdot 1$ & 0.90 & $276 \ldots$ \\
2 & 0.74 & 425 \\
3 & 0.67 & 469 \\
4 & 0.62 & 496 \\
5 & 0.56 & 523 \\
6 & 0.52 & 539
\end{tabular}

Operating Flexibility - The above simple model suggests that the FCRPS must be flexible enough to accept perturbations in generation unanticipated at lag 1 hour that exceed $540 \mathrm{MW} 5 \%$ of the time and $700 \mathrm{MW} 1 \%$ of the time. At lag 2, the predictability based on persistance drops significantly with the $5 \%$ exceedance value of uncertainty increasing to $830 \mathrm{MW}$ and the $0.1 \%$ value to $1094 \mathrm{MW}$. The present controling plants on the FCRPS may not be able to accept random fluctuations of this magnitude under the existing operating constraints. 
There are possibilities for smoothing the wind output to make it more acceptable to the FCRPS. Pumped storage driven by wind generators could $3_{i}$

smooth the output from the network by clipping extreme variations in either direction. Also combustion turbines might compensate for large one or two hour variations in wind. Production costs from this operation would be small due to the infrequent occurrence of large wind fluctuations. Another possibility is control of the wind generators so as to spill the wind when positive fluctuations exceed prescribed linits. Combustion turbines could work here to pick up when wind slackens beyond the acceptable limits. There are no doubt other engineering solutions including some which would make use of interregional interties.

This study purposely looked only at the $3000 \mathrm{MW}$ system identified in the OSU study. It may turn out that some lesser capacity may be optimal , from a hydro standpoint. Optimality of the resource mix is being studied now by BPA and the PNUCC. Other reports will focus on choosing the best mix.

Overgeneration Analysis - Overgeneration during off-peak hours is not a new problem--it has occurred in recent years during some months when nightime generation requirements are less than the generation forced by minimun streamflow constraints.

The objective of this analysis was to characterize the overgeneration component due to the wind network by estimating the magnitude on an average annual basis and also by month. Overgeneration is calculated by subtracting the estimated minimum streamflow from the residual hydro. 
Minimum streamflow was assumed to equal $2000 \mathrm{MW}$ of hydro generation in the initial studies. These results were modified to include a case with a $3140 \mathrm{MW}$ minimum generation requirement.

Two seperate models were used to calculated residual hydro. (See Figure 1, Case 1 and Case 2.) Multiple runs were made on both models and average overgeneration was calculated. The study year for both models was 1990. Projected 1990 loads were derfved from the West Group Area (WGA) Hourly Load and Resource Allocation Program. Overgeneration estimates are summarized in Table 6 for both Case 1 and Case 2, with and without wind.

Case 1 consisted of varying ten patterns of unplanned thermal outage with the single pattern of wind generation as described in Section II, Wind Network Description. Overgeneration resulted in an average annual firm energy loss amounting to 3.4 average annual megawatts which represents 0.4 of one percent of the average annual energy gain due to the wind while the September loss amounts to 42 average megawats or approximately 5 percent of the September wind gain.

Case 2 consisted of estimating thermal plant performance for forty one-year intervals utilizing a Monte Carlo simulator. The average of. these hourly runs was then subtracted from the single hourly pattern of wind generation and the overgeneration was calculated. Overgeneration resulted in an average annual firm energy loss amounting to 11.6 average annual megawatts which represents 1.0 percent of the average annual energy gain due to the wind while the September loss amounts to 71 average megawatts or 7.6 percent of the September wind energy. Standard 
deviation of overgeneration values for the year equalled 20.5 megawatts. Figure 9 utilizes the data generated in Case 2 to depict the magnitude and number of hours in a year overgeneration occurs. Figure 10 is pictorial representation of the data in Table 6 for Case 2 .

Although the two models yield slightly different results, the pattern and magnitude of the overgeneration is similar. Both models show that the degree of overgeneration is not large when compared to the amount of energy gained from the wind resource. In addition, overgeneration occurs without wind also. The added overgeneration resulting from wind would occur with any new resource and is not a characteristic unique to wind. It should be noted that overgeneration is not necessarily a waste. It likely would be marketed as secondary energy. The overgeneration component of wind energy would act as a discount to the value of wind as a firm energy resource.

Two important assumptions were made in the initial study of overgeneration discussed above: 1) Minimum streamflow was set at $2000 \mathrm{MW}$, and 2) Existing capacity-energy exchange contracts were assumed to have terminated prior to the year under study. Both assumptions impact the amount of overgeneration.

New estimates of minimum streamflows were obtained subsequent to the simulations for both Case 1 and Case 2. The new estimates are 2470 MW in the winter and $3140 \mathrm{MW}$ in the sumer and experience indicates that these levels would increase rather than decrease with the passing of time. Larger minimum streamflows rasult in more overgeneration. Based on the new estimates of minimun streamflows the average overgeneration component increased to 40 average megawatts (Case 2). 
Table 6

OVERGENERATION BY MONTH ASSUMING 2000 MN MINIMUM STREAMFLOW

(Average Megawatts)

\begin{tabular}{|c|c|c|c|c|}
\hline \multirow[b]{2}{*}{ Month } & \multicolumn{2}{|c|}{ Case 1} & \multicolumn{2}{|c|}{ Case 2} \\
\hline & With Wind & No Wind & With Wind & No Wind \\
\hline JAN & - & - & - & - \\
\hline FEB & - & - & - & - \\
\hline MAR & - & - & 2 & $\dot{-}$ \\
\hline APR & - & - & 3 & - \\
\hline MAY & - & - & 1 & - \\
\hline JUN & - & - & 9 & - \\
\hline JUL & - & - & 15 & $I$ \\
\hline AUG 1 & - & - & 7 & - \\
\hline AUG 2 & 3 & $<1$ & & \\
\hline SEP & 42 & 4 & 71 & 13 \\
\hline OCT & - & - & 29 & 3 \\
\hline NOV & - & - & 1 & - \\
\hline $\mathrm{DEC}$ & - & - & 1 & - \\
\hline $\begin{array}{c}\text { Average } \\
\text { Annual MW }\end{array}$ & 3.4 & 0.3 & 11.6 & 1.5 \\
\hline
\end{tabular}


FIGURE 9

RESIDUAL HYDRO BELOW MINIMUM STREAMFLOW

WY 1990 - 40 YEAR TOTAL

( Case 2 - 2000 MW MINIMUM STREAMFLOW)

NUMBER HOURLY OCCUARENCES

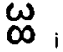

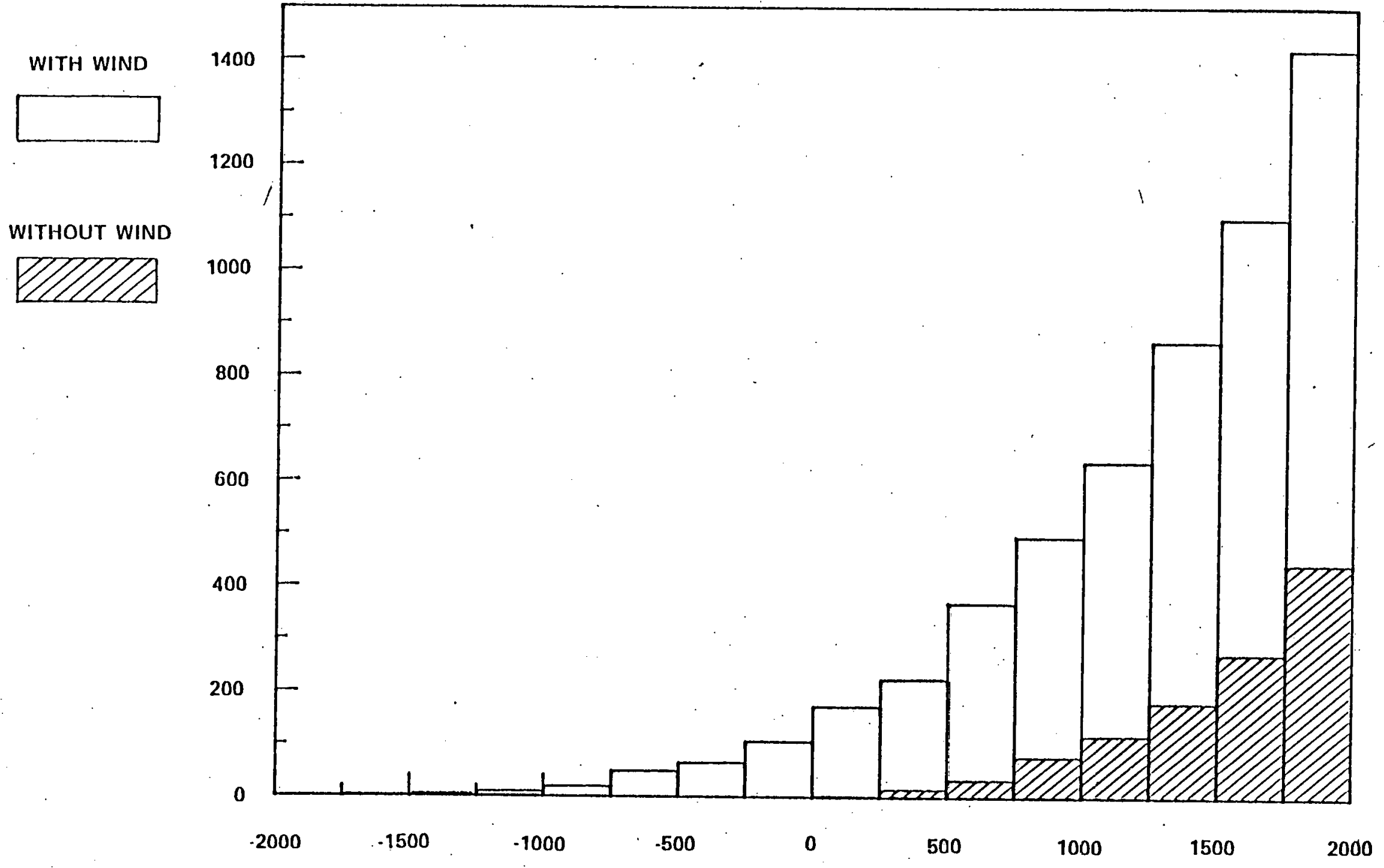

RESIDUAL HYDRO (MW) 
FIGURE 10

AVERAGE OVERGENERATION BY MONTH

WY 1990 - 40 YEAR TOTAL.

Case 2 - 2000 MW MINIMUM STREAMFLOW

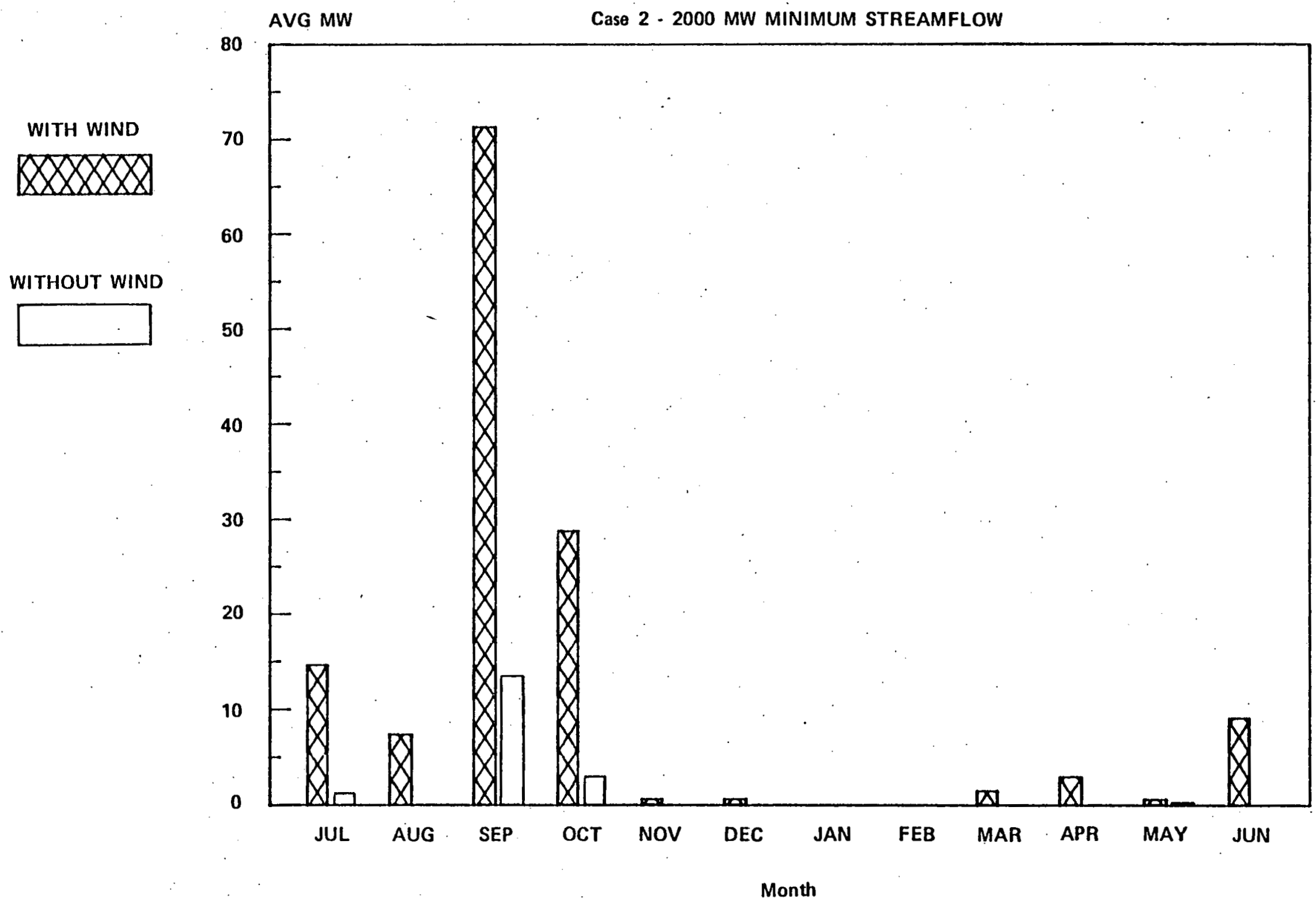


If the existing capacity-energy exchange contracts were extended, the overgeneration values would again increase. A saparate investigation $\underline{2}$ has shown that extending the contract through the study year increases the firm energy loss from 0.4 of one percent of the annual wind energy to 3.5 percent of the annual wind energy. Again the overall conclusions remain unchanged.

2/.BPA Memorandum dated November 20, 1979, A. C. Balci (PRC),

"Influence of Extending Existing Capacity on WGA System Operation." 


\section{Summary of Results}

The following statements represent the key findings of this study. All findings are based on the integration of the $3000 \mathrm{MW}$ wind network described in Section II.

1. Generation from the wind should be considered a firm energy resource during a critical water year and no capacity credit should be granted for the network under study, at least until additional studies are performed. Gross energy production of the 3000 MW network studied equaled about 1000 average megawatts. Assumming worst case operating and streamflow conditions, up to $40 \%$ of this energy would not be useable. Additional studies are necessary to determine the characteristics of the optimum wind network which would maximize the net energy production.

2. The Columbia River Power System can assimilate at least $3000 \mathrm{MW}$ of wind power without violating existing seasonal reservoir and hydraulic operating constraints. Hourly studies, however, indicate up to a $24 \%$ increase in the number of hours during which flow constraints are observed: Maximum change of tailwater and forebay elevations, maximum rate of hourly discharge, and average weekly generation are also impacted by the addition of the $3000 \mathrm{MW}$ network. Hourly impacts may be sensitive to wind network configuration. Further studies are necessary to completely evaluate impacts on hourly operations. 
3. The $3000 \mathrm{MW}$ wind power system under study, would force overgeneration amounting to about 40 average megawatts per year. This increment of energy would be a subtraction from the value of the wind energy. as a firm resource. The overgeneration occurs primarily in the July-October time period with maximum overgeneration occuring in September. If additional minimum streamflow constraints are put on the FCRPS, the overgeneration component will increase.

4. Given the 1985 load-resource (1979 PNUCC West Group Forecast), which shows a firm deficit of $1490 \mathrm{MW}$, the wind. system under study would free secondary energy allocated to this deficit without the wind network and would increase export potential, by about 640 average megawatts. $47 \%$ or about $300 \mathrm{MW}$ of this potential would be marketable over existing intertie capacity. In the 1990 load-resource condition, which shows a firm surplus of $152 \mathrm{MW}$, the export potential increases to about $800 \mathrm{MW}$ assuming no transmission capacity constraint.

5. Given the 1979 PNUCC West Group forecast of loads and resources, and assuming that the gross energy production of the wind network could be assimilated into the existing system, the cumulative probability of insufficient firm energy load carrying capability thru 1990 would decrease from $81 \%$ without wind to $36 \%$ with wind. For total loads the cumulative probability through 1990 of an insuffiency decreases from $98 \%$ to $90 \%$ due to the wind network under study. 
6. Given that: (1) the hydro system receives the full burden of absorbing the variation in wind power output, (2) wind generation cannot be forecast on a short-term basis, and (3) a mediar streamflow level occurs, approximately one quarter of the annual energy production from the network studied would not be useable due to scheduling and operating difficulties imposed by the FCRPS.

Seasonal or average aspects of wind integration do not appear to pose any significant difficulties. However, hourly studies indicate a increase in operating difficulties. Further study is required of the power scheduling and dispatching aspects of wind integration: System reserve requirements due to wind energy and system stability analysis have not been covered here and will require attention. (See Section $V$, Recommendations for Future Work.) of primary concern in all wind integration studies is the effect of peaking capacity credit on conclusions reached in seasonal and monthly aspects of the study. The inability to assign a firm value is primarily due to the nature of the wind resource. This limitation must be noted when analyzing the study results. It is an area where additional work is required. 


\section{Recomendations for Future Work}

The primary benefit of these analyses is the refinement of technical issues involved in integrating a large wind energy conversion system into the existing network. With this in mind, along with the assumptions and limitations stated throughout the study, the following recommendations are made to assist in defining and improving further integration studies.

1. A study should be conducted to investigate the development of a methodology which assigns a peaking value to the wind resource which is compatible with models currently utilized by BPA and other Northwest utilities.

2. Further hourly studies should be conducted which concentrate on real-time operational aspects of scheduling and dispatching a wind resource. Particular emphasis should be placed on utilizing current load data and simulating the wind resource coincident with the load. By not projecting system operation into the future it will be possibie to keep variables to a minimum.

3. Prospecting for wind sites should include the identification of sites where high winds are coincident with high loads. Such sites should be instrumented in order to determine benefits of siting wind turbines for peak operation. 
4. Futher studies should be initiated which examine the effect of pumped storage on the operation of wind turbine facilities.

5. Studies should be conducted to determine the "optimum" network configuration and wind energy level for integration into the FCRPS. Particular emphasis should be placed on mixing wind energy with other alternative and renewable resources. 
Capacity - The maximum load that a machine, station, or syster can carry under existing service conditions. Equivalent terms: peak capability, peak generation, firm peakload, carrying capability.

Capacity Credit - The, dependable capacity of systen facilities available for serving load after allowance for required reserve capacity.

Capacity-Energy Exchange Contracts - A power exchange contract in which capacity and energy are delivered in return for energy only, but in greater amounts then that amount delivered with the capacity. This difference in energy represents full or partial payment for the capacity and energy delivered.

Capacity Factor - The ratio of the average load on a generating resource to its capacity rating during a specified period of time.

Coefficient of Correlation - For two random variables, the ratio of their covariance to the product of their standard deviations.

Coefficient of Variation - A measure of relative variation which is given by the ratio of the standard deviation of a set of data to their mean, thus expressing the magnitude of their variation relative to their average size.

Covariance - The expected value of the product of the deviations of two random variables from their respective means. 
Critical Hydro Period - For the Northwest, that portion of the historical 40-year streamflow record which, when combined with the draft of all available reservoir storage, will produce the least amount of energy, with energy being used according to seasonal load patterns.

Firm Energy - Electric energy which is intended to have assured availability to the customer to meet all or any agreed upon portion of his load requirements.

Firm Power - Power which is guaranteed by the supplier to be available at all times except for reason of certain uncontrollable forces or continuity of service provisions. Equivalent term: Firm Capacity.

Interruptible Power - Power that, by contract, can be interrupted in the event of a capacity or energy deficiency on the supplying system, generally heavy industrial loads on the BPA system.

Load Factor - The ratio of average load to the peak load during a specified period of time.

Loss of Load - Occurs only when the capability of the generating capacity remaining in service is exceeded by the system load. -

Loss of Load Probability (LOLP) - This is defined as the fraction of any period of time which loss of load may be expected to occur due to forced capacity outage in excess of reserves. 
Minimum Straamflow - The amount of streamflow, which must be maintained to avoid violating various hydraulic, environmental, and navigational constraints.

Overgeneration - The power available when residual load drops below the generation produced from minimum streamflows. Overgeneration may or may not be useable in secondary markets or markets outside the region.

Peaking Capacity - Generating capacity available to assist in meeting that portion of the load which is above base load. The maximum output of a generating plant or plants during a specified peak-load period.

Peak Firm Capacity - Generating capacity which is guaranteed by the supplier to be available to assist in meeting that portion of the load which is above baseload except for reasons of certain uncontrollable forces.

Peak Reserves - Extra generating capacity available to meet unanticipated demands for power in that portion of the load which is above baseload. These unanticipated demands can be for power or to generate power in the event of loss of generation resulting from scheduled or unscheduled outages of regularly used generating capacity. Reserve capacity provided to meet the latter is also known as forced outage reserve.

Reserve Capacity - Extra generating capacity available to meet unanticipated demands for power or to generate power in the event of loss of generation resulting from scheduled or unscheduled outages of regularly used generating capacity. Reserve capacity provided to meet the latter is also known as forced outage reserve. 
Residual Hydro - See Residual Load.

Residual Load - That portion of the electrical load which is served from hydro resources. Projected Residual Load equals the total projected load less the scheduled thermal generation less other resources (e-g. wind). Synonymous with Residuai Hydro.

Secondary Energy - Energy which is available when streamflow is greater than critical level and represents energy that is generated in excess of firm energy.

Surplus Energy - Energy generated that is in excess of the firm needs of the Pacific Northwest.

West Group Area - The operating area including the entire State of Washington, the northern part of Idaho, all of Oregon except for a small eastern part of the State, a portion of northern California, the Bonneville Power Administration (BPA) and Pacific Power and Light Company service areas in Montana, the BPA loads. in southern Idaho and contiguous areas in Nevada, Utah, and Wyoming, and WPRS resources in southern Idaho. 


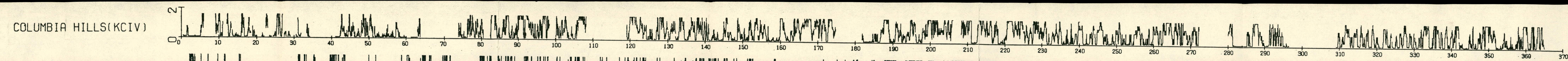
IIT of 


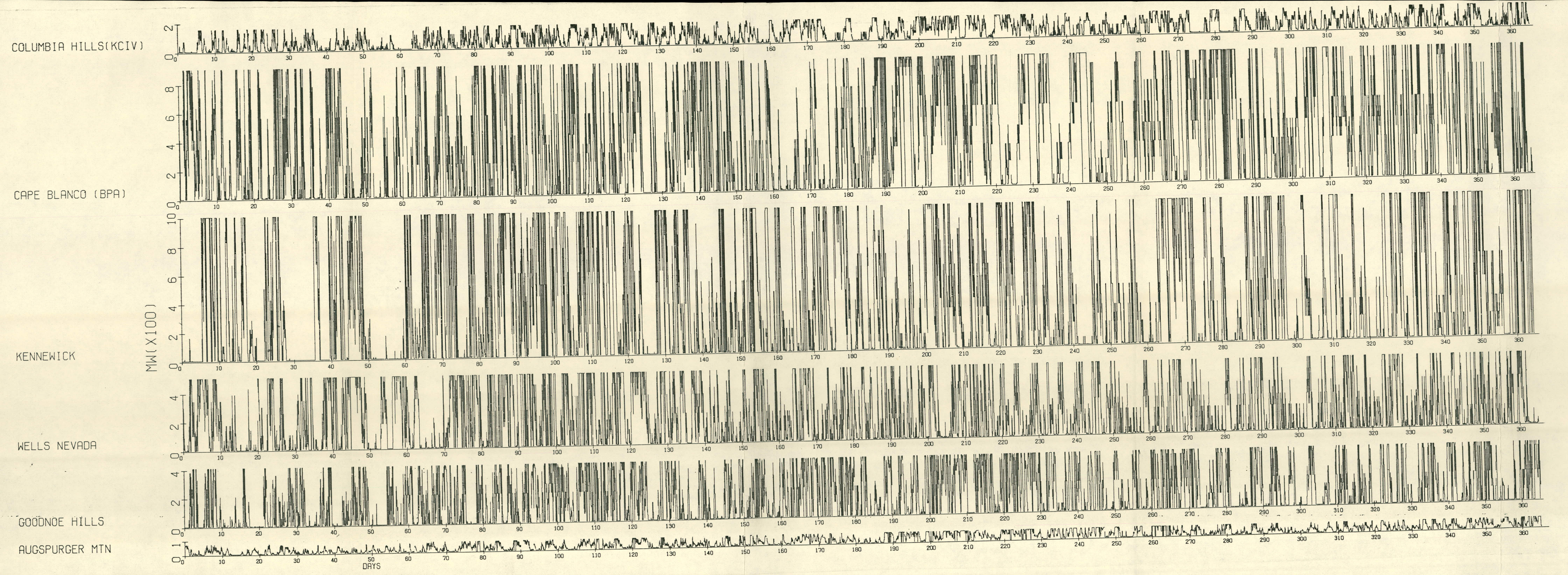




\section{HOURLY OUTPUT BY STATION}

-REPRESENTATIVE WEEK-

(JUNE 3, 1977-JUNE 9, 1977)

\section{COLUMBIA HILLSIKCIV}

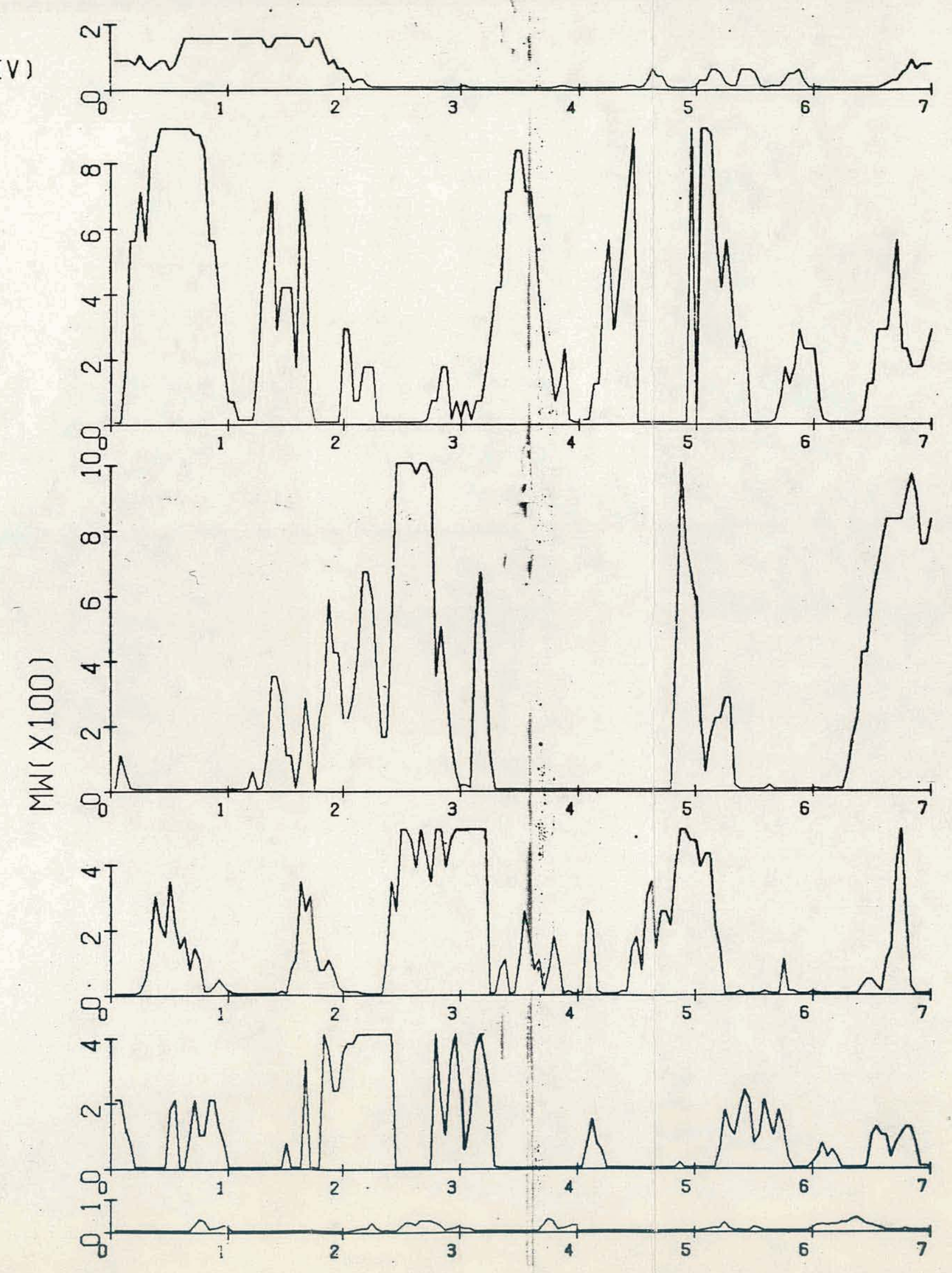

CAPE BLANCO (BPA)

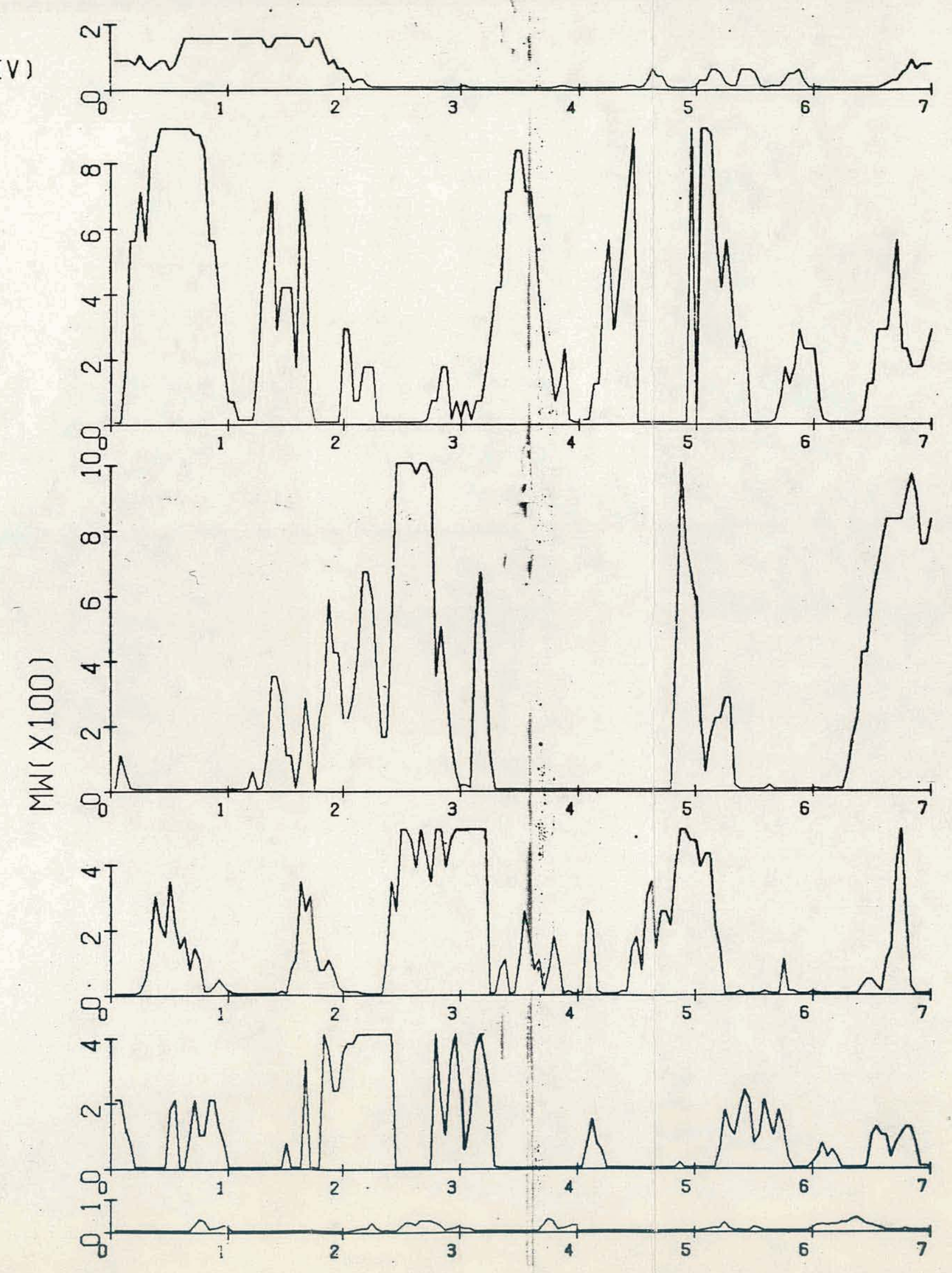

GOODNOE HILLS

AUGSPURGER MTN 


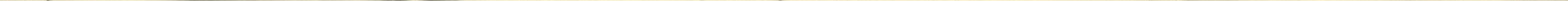




\section{TOTAL NETWORK HOURLY OUTPUT}

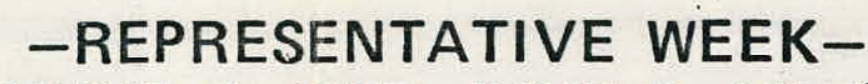

(JUNE 3, 1977-JUNE 9, 1977)

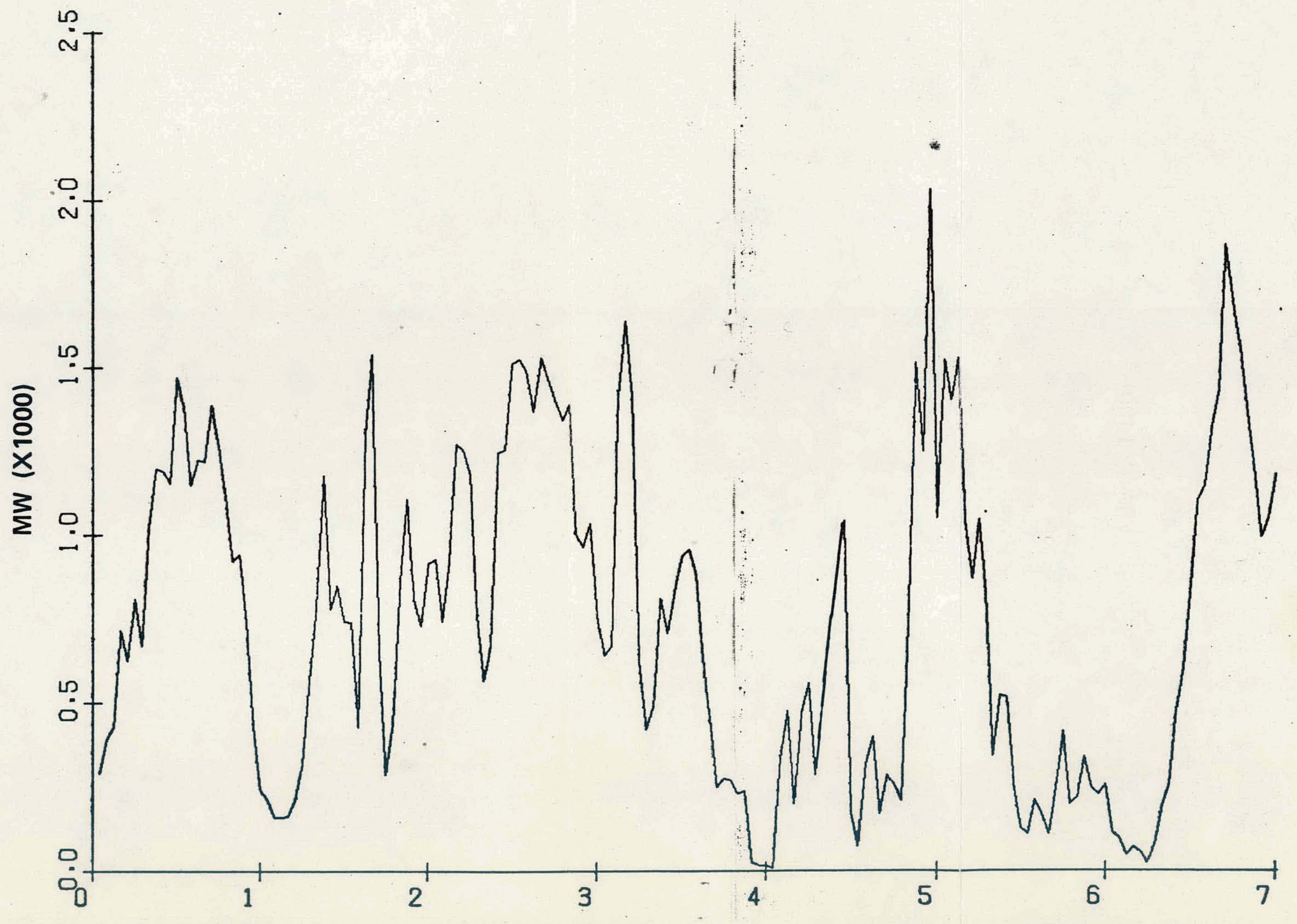




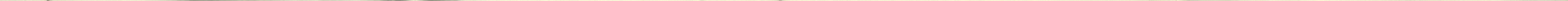




\section{APPENDIX G}

Table Gl

PROBABILITY OF NOT MEETING FIRM LOADS - NO WIND

\begin{tabular}{|c|c|c|c|c|c|}
\hline \multirow[b]{2}{*}{ YEAR } & \multicolumn{3}{|c|}{ SEASONS 1/ } & \multirow{2}{*}{$\begin{array}{l}\text { Total 2/ } \\
\text { Year }\end{array}$} & \multirow{2}{*}{$\begin{array}{c}\text { Cumulative } 2 / 3 / \\
\text { (Yearly) }\end{array}$} \\
\hline & 1 & 2 & 3 & & \\
\hline 80 & .03 & .04 & .10 & .13 & .13 \\
\hline 81 & .06 & .07 & .11 & .16 & .25 \\
\hline 82 & .10 & .07 & .12 & .21 & .39 \\
\hline 83 & .08 & .14 & .12 & .21 & .49 \\
\hline 84 & .15 & .13 & .13 & .27 & .61 \\
\hline 85 & .11 & .08 & .07 & .20 & .67 \\
\hline 86 & .05 & .05 & .06 & .12 & .70 \\
\hline 87 & .02 & .03 & .03 & .07 & .72 \\
\hline 88 & .04 & .05 & .06 & .12 & .75 \\
\hline 89 & .05 & .04 & .04 & .11 & .77 \\
\hline 90 & .07 & .05 & .06 & .14 & .81 \\
\hline
\end{tabular}

Table G2

PROBABILITY OF NOT MEETING TOTAL LOADS - NO WIND

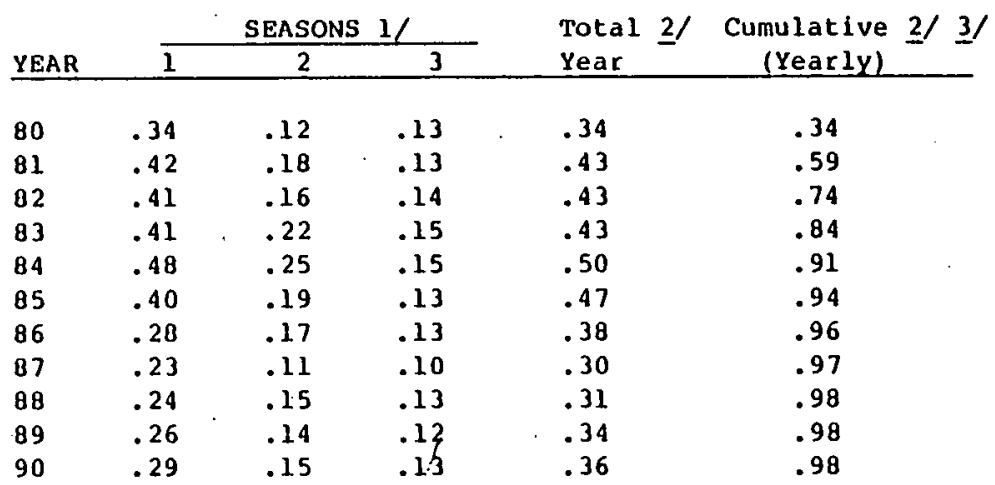

Table G3

PROBABILITY OF NOT MEETING FIRM LOADS - WITH WIND

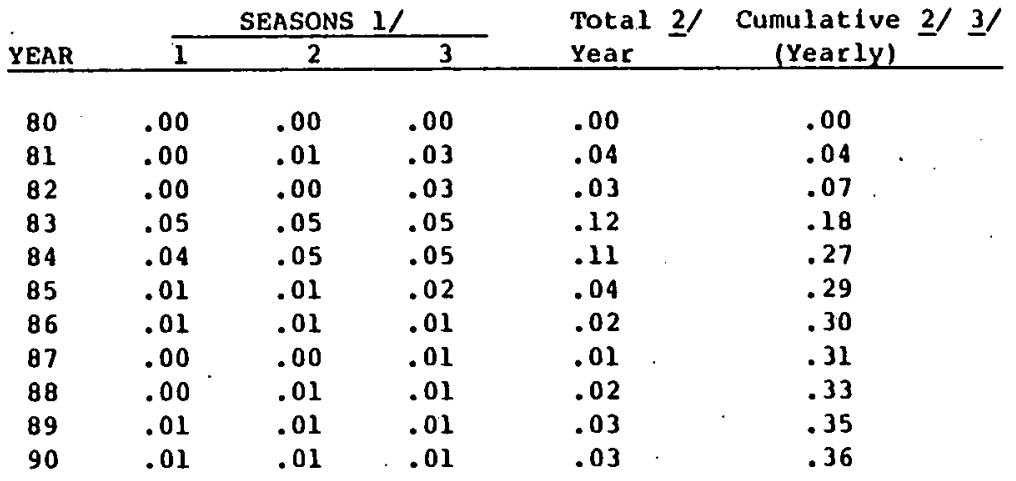

Table G4

PROBABILITY OF NOT MEETING TOTALS LOADS - WITH WIND

\begin{tabular}{|c|c|c|c|c|c|}
\hline \multirow[b]{2}{*}{ YEAR } & \multicolumn{3}{|c|}{ SEASONS $1 /$} & \multirow{2}{*}{$\begin{array}{l}\text { Total } 2 / \\
\text { Year }\end{array}$} & \multirow{2}{*}{$\begin{array}{c}\text { Cumulative } 2 / 3 / 3 / \\
\text { (Yearly) }\end{array}$} \\
\hline & 1 & 2 & 3 & & \\
\hline 80 & .03 & .04 & .10 & .14 & .14 \\
\hline 81 & .11 & .11 & .10 & .21 & .27 \\
\hline 82 & 19 & .07 & .11 & .28 & .43 \\
\hline 83 & .34 & .15 & .12 & .38 & .61 \\
\hline 84 & .31 & .17 & .13 & . 37 & .73 \\
\hline 85 & .21 & .09 & .09 & .28 & .78 \\
\hline 86 & .15 & .07 & .08 & .22 & .81 \\
\hline 87 & .09 & .04 & .06 & .15 & .84 \\
\hline 88 & .08 & .05 & .09 & .17 & .85 \\
\hline 89 & .12 & .05 & .07 & .19 & .88 \\
\hline 90 & .12 & .06 & .09 & .20 & .90 \\
\hline
\end{tabular}

1/ Season 1: Sep-Dec; Season 2: Jan-Apr; Season 3: May-Aug

2/ Annual probabilities are not functions of the tallied season probabilities; nor are the cumulative probabilities functions of annual probabilities. Each set of probabilities is a result of direct application of tally procedures.

3/ Cumulative figures reflect the probability of experiencing a negative surplus any time between 1980 and the year shown. 


\section{APPENDIX H}

\section{WIND TURBINE CHARACTERISTICS}

The maximum power available to a wind generator is determined by the kinetic energy contained in the air mass being intercepted by the wind turbine. With a given air density (defined by altitude and air temperature), this maximum power is a direct function of the cube of the wind velocity and of the area being swept by the turbine blades.

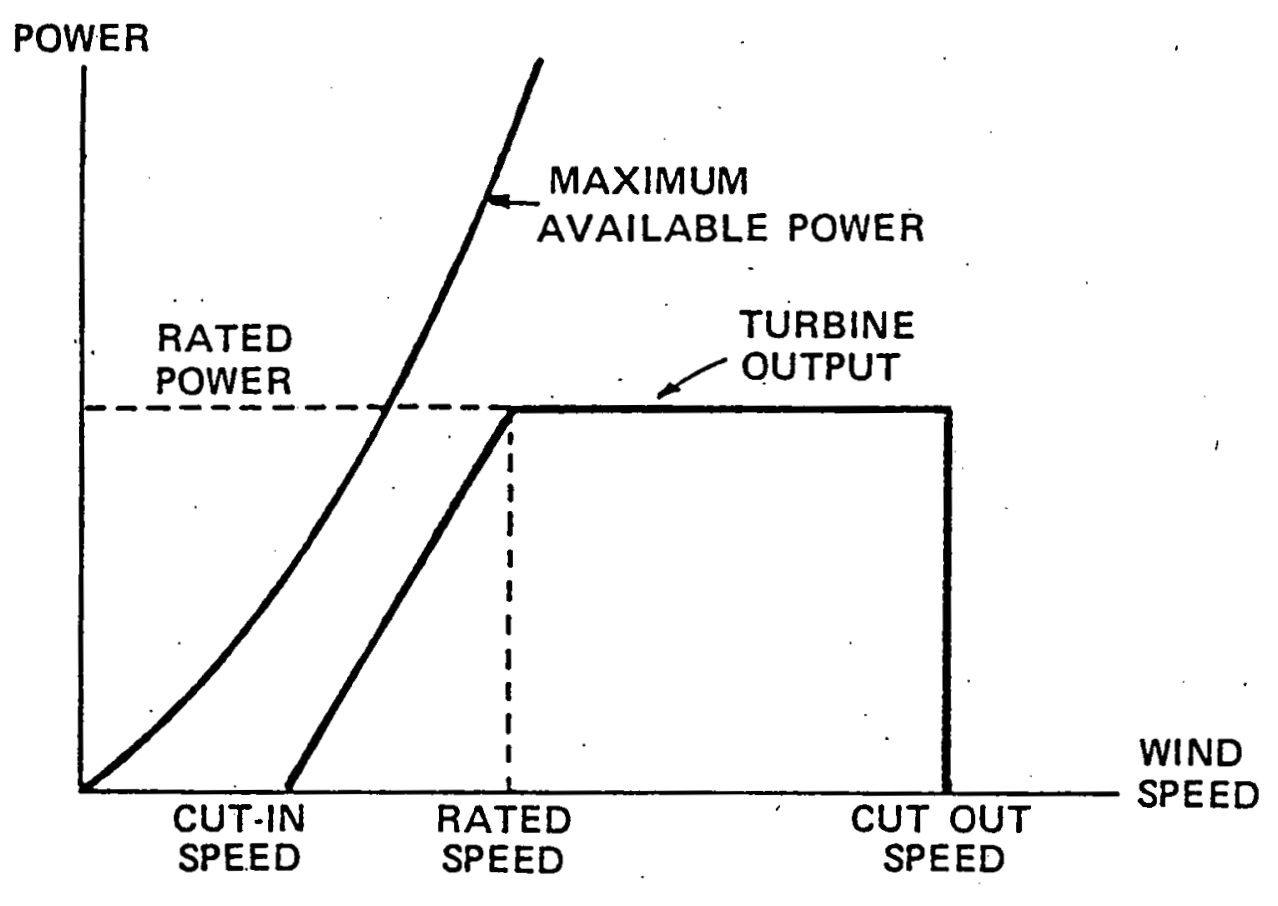

WIND TURBINE OUTPUT

The turbine begins generating power at a threshold wind velocity, known as the cut-in speed. As the wind velocity increases, the power output increases until the machine output reaches its maximum rating. As the wind continues to increase in velocity, the turbine output maintains its rated 
output until the cut-out velocity is reached, at which time the turbine is shut down to prevent damage from high winds. Although it would seem that a substantial amount of energy would be lost because of high speed shutdown, winds do not generally sustain velocities above cut-out for prolonged periods of time. On an annual basis only a very small portion of energy is lost. Cut-in and cut-out speeds can be modified to take advantage of sitespecific conditions. As a general rule, the energy production at a given site will be maximized when the rated speed of the wind turbine is twice the average annual wind speed.

The table below summarizes the characteristics of the turbines used in this study.

Wind Turbine Characteristics

\begin{tabular}{|c|c|c|c|}
\hline ed Power & $\begin{array}{c}\text { Cut-In Speed } \\
\text { (mph) }\end{array}$ & $\begin{array}{l}\text { Rated Speed } \\
\text { (mph) }\end{array}$ & $\begin{array}{c}\text { Cut-Out Speed } \\
\text { (mph) }\end{array}$ \\
\hline
\end{tabular}

$2.5 \mathrm{MW}$

14

27

45

4.5 MW

14

35

45 